\title{
La cobertura de la reforma educativa en México Un asunto de medios y políticas
}

\author{
Newspaper Coverage of Educational Reform in Mexico: \\ An Issue of Media and Policies
}

Gloria Del Castillo Alemán y Georgina Flores-lvich*

Resumen: El propósito de este artículo es sistematizar la cobertura mediática que recibió la reforma educativa mexicana entre 2012 y 2015 en cuatro diarios impresos de circulación nacional. Los hallazgos contribuyen a conocer la atención mediática que recibió la reforma educativa (RE). Se asume que la prensa nacional escrita privilegió en su cobertura las decisiones que representaron cambios drásticos de políticas para los distintos actores que protagonizaron la reforma. Esto ofrece algunas coordenadas para comprender el papel que la prensa jugó en el proceso. Se concluye que la prensa favoreció la cobertura de decisiones y acciones de mayor controversia en la trayectoria de las políticas educativas de los últimos veinte años y dejó en segundo plano aspectos igualmente trascendentales, lo cual invita a reflexionar sobre su papel en los procesos de políticas y la existencia de estrategias de comunicación que acompañen a este tipo de procesos de transformación.

Palabras clave: medios, atención mediática, agenda, proceso de políticas, reforma educativa.

Abstract: The article aims to systematize the media coverage received by the Mexican educational reform between 2012 and 2015 in four national daily newspapers. The findings contribute to know what media attention the RE received. It is assumed that the written national press privileged in its coverage the decisions that represented drastic changes of policies for the different actors that have carried out the reform, which offers some coordinates to understand what role it played in this policy process. It is concluded that the press favored the coverage of decisions and actions of greater controversy in the trajectory of the educa-

*Gloria Del Castillo Alemán es profesora-investigadora de tiempo completo en la Facultad Latinoamericana de Ciencias Sociales (Flacso), Carretera al Ajusco 377, Héroes de Padierna, Tlalpan, 14420. Tel: 30000257. Correo-e: gloria@flacso.edu.mx. orcid: 0000-0002-0812-8792. Georgina Flores-Ivich es profesora-investigadora asociada de tiempo completo en la Facultad Latinoamericana de Ciencias Sociales (Flacso), Carretera al Ajusco 377, Héroes de Padierna, Tlalpan, 14420. Tel: 3000 0200. Correo-e: gfloresivich@gmail.com. ORCID: 0000-0001-8879-3268.

Artículo recibido el 3 de agosto de 2017 y aceptado para su publicación el 5 de noviembre de 2018 .

DoI: http://dx.doi.org/10.29265/gypp.v28i2.628 
tional policies of the last twenty years and left in second plane equally trascendental aspects, which invites to reflect on its role in the processes of policies and the existence of communication strategies that accompany this type of transformation processes

Keywords: media, media attention, agenda setting, policy process, education reform.

\section{INTRODUCCIÓN}

T os medios de comunicación han sido objeto de atención en el campo de la $\_$política pública desde principios de la década de 1970 (Downs, 1972b), pero sólo recientemente existe el interés de relacionarlos con el proceso de las políticas públicas (Koch-Baumgarten y Voltmer, 2010) para indagar su incidencia en los resultados de políticas, es decir, conocer en qué medida dan forma a los debates que se desarrollan en ellos, cuánta influencia ejercen en las opiniones del público y cuáles son los aportes de vincular analíticamente medios y políticas públicas para la toma de decisiones.

Los hallazgos de esta agenda de investigación no son concluyentes en torno a la influencia de los medios en el proceso de las políticas públicas, pero se asume que pueden ser un factor relevante a considerar para comprender de mejor manera la dinámica de las políticas en las democracias modernas (Koch-Baumgarten y Voltmer, 2010). La evidencia indica que la opinión que se vierte en los medios permea la percepción del público y lo predispone ante asuntos concretos que son producto de la acción gubernamental (Wolfe, Jones y Baumgartner, 2013). Este hecho posteriormente merece la atención de una estrategia política gubernamental de comunicación que refuerce o que revierta lo que los políticos considerarían "una mala prensa": opiniones que desde su perspectiva distorsionan el sentido de sus decisiones políticas o de política pública.

La relación entre medios y políticas públicas es un tema que abre distintas rutas de investigación en función del ángulo disciplinario que se elija para ello. Aquí decidimos articular una mirada que nos condujo a ubicar la atención mediática (media attention) como el principal objeto de estudio, entendiendo por ésta la decisión que toman los medios sobre qué cobertura merecen ciertos temas y actores que son parte de un proceso de políticas públicas. El objetivo de esta investigación fue realizar un estudio descriptivo acerca de la cobertura que recibió la última reforma educativa (RE) en la prensa mexicana entre 2012 y 2015. Los resultados del análisis cuantitativo de las notas permiten analizar los patrones en la cobertura y establecer una relación con los momentos clave de la reforma.

Se consideró que los medios representan un espacio donde tuvo lugar el debate público entre las opiniones de distintos actores en torno a la RE, sin olvidar 
que son un actor que decide qué temas y qué actores merecen mayor o menor atención, a partir de lo cual se genera una agenda política de medios. La RE es el proceso decisional político-técnico ${ }^{1}$ a través del cual el gobierno federal (20122018) buscó impulsar un conjunto de transformaciones orientadas a revertir diversos problemas detectados en el sistema educativo, lo que adquiere visibilidad pública por la atención mediática que les otorga la prensa nacional escrita.

El producto de la interacción entre los medios y el proceso de políticas es la agenda que se genera en los medios impresos nacionales. Para hacerla observable se focalizó la indagación en la atención mediática: qué temas de la RE destacan los periódicos, cuáles de ellos adquieren mayor presencia, qué opiniones atrapan la atención de la prensa, cuáles de éstas reciben mayor atención, cuáles favorecen y cuáles rechazan la RE.

Así, la agenda mediática es el espacio donde los distintos actores expresan sus opiniones y posicionamientos con relación a un conjunto de decisiones gubernamentales de interés público; de aquí su naturaleza de agenda política. Desde esta perspectiva, destacan por lo menos cuatro objetos de estudio: a) los actores, b) sus opiniones, $c$ ) sus posturas y $d$ ) los espacios donde vierten sus puntos de vista. Los actores son agentes gubernamentales y no gubernamentales; sus opiniones son las que éstos emiten acerca de temas o aspectos de la RE; sus posturas son su posicionamiento a favor o en contra de la RE, y los espacios son los medios impresos específicos donde se hacen públicas éstas.

El periodo de estudio abarca del 1 de diciembre de 2012 al 31 de diciembre de 2015, en cuatro diarios escritos de circulación nacional: El Universal, El Financiero, Reforma y La Jornada, y se focaliza en: a) el tamaño, b) la posición adoptada por los medios, $c$ ) la posición adoptada por los actores y d) los temas que destacan los medios, es decir, la atención mediática.

Para esta sistematización se construyó una base de datos que contiene la totalidad de las notas periodísticas referidas a la RE en el periodo mencionado. Se analizaron 6213 notas en 37 meses de cobertura. Esta base original fue construida especialmente para esta investigación, que es una aproximación al estudio de la

\footnotetext{
${ }^{1}$ La dimensión técnica del proceso se refiere a la articulación de decisiones, acciones y metas (solución del problema). La dimensión política, a la interacción de actores en el sistema político y en la prensa, donde tiene lugar un debate de políticas públicas, en el que "luchan" las opiniones de tales actores que son parte de un proceso de políticas (Howlett, Ramesh y Perl, 2009). El proceso de políticas públicas se entiende como la dinámica producto de las decisiones y acciones orientadas a mitigar una situación indeseable para una población en un momento y lugar específicos, donde la naturaleza de la dinámica está dada por la interacción que se genera entre la maquinaria del Estado, los distintos actores políticos que se involucran por diferentes motivos en un proceso de políticas y el público (Petridou, 2014).
} 
cobertura mediática de las políticas públicas en México, en la medida en que permite relacionar tal cobertura con las distintas fases del proceso de la RE: sus orígenes, diseño e implementación. Esto permite la reconstrucción de los así llamados "ciclos de atención", en el sentido de que la cobertura mediática es episódica e irregular y pone atención en algunos temas e ignora otros (Boydstun, 2013).

El artículo comprende cinco partes. En la primera se aborda la revisión de la literatura acerca de los debates sobre la función de los medios de comunicación en el proceso de políticas. En la segunda parte, a fin de ofrecer argumentos sobre su relevancia como caso de estudio, se presenta el contexto político en que emerge la RE como integrante del conjunto de políticas públicas que el gobierno federal mexicano (2012-2018) decidió adoptar para impulsar cambios estructurales que, en su visión, reorientaran el desarrollo del país. En la tercera se describe el método de análisis. En la cuarta parte se presenta el análisis de la cobertura que ha recibido la RE y, finalmente, se exponen las conclusiones junto con algunas reflexiones sobre la utilidad práctica de realizar estudios de cobertura mediática de políticas públicas.

\section{LA RELACIÓN ENTRE EL PROCESO DE POLÍTICAS Y LOS MEDIOS DE COMUNICACIÓN}

El proceso de políticas públicas es el interés intelectual central de los estudios de políticas públicas. ${ }^{2}$ Existen distintas definiciones del proceso de políticas, pero en su mayoría coinciden en que su complejidad se deriva, en buena medida, de los distintos elementos que interactúan en su desarrollo y de los muy diversos aspectos que lo conforman: a) actores involucrados (grupos de interés, agencias gubernamentales y legislaturas, investigadores, medios de comunicación) en uno $\mathrm{o}$ varios aspectos del mismo, $b$ ) instituciones, $c$ ) niveles de gobierno, $d$ ) valores $\mathrm{e}$ intereses de distinto tipo en cada aspecto del mismo, que a su vez son procesos (Sabatier, 2007; Schlager y Weible, 2013; Petridou, 2014).

Los estudios de políticas generalmente buscan reconstruir y en consecuencia evaluar a posteriori los distintos momentos de los procesos decisionales que comienzan con la definición del problema y la formulación de la agenda, pasando por el diseño y el proceso de implementación. Derivado de lo anterior, se requie-

\footnotetext{
${ }^{2}$ Desde un enfoque de política pública hay que distinguir entre análisis de políticas públicas y estudios de políticas, ya que responden a construcciones teórico-metodológicas distintas. La singularidad de los estudios radica en que su pretensión intelectual básica es comprender la racionalidad según la cual ocurren los procesos decisionales, asumiendo que dicha comprensión exige necesariamente no separar las dimensiones técnica y política del proceso, a fin de captar y comprender su dinamismo y anticipar el alcance y resultados del mismo (Del Castillo, 2014).
} 
re el uso de un marco de análisis que permita captar los distintos componentes que moldean los procesos decisionales y que generan influencia tanto en el público como en las élites políticas y que, además, generan un efecto en los resultados concretos de las políticas. En este sentido, los medios de comunicación constituyen uno de los elementos para comprender un aspecto estratégico del proceso político de las políticas públicas.

Las relaciones entre los medios, el público y los hacedores de política pública constituyen el centro de muchas de las interacciones que se dan en los procesos de política y abarcan un número importante de intereses de investigación, incluyendo el rol de los medios en la formación de la opinión pública y de las políticas públicas y el grado en que éstas siguen o lideran la opinión pública (Soroka, 2002). A pesar de que en los últimos años la relación entre medios y políticas públicas ha generado una línea de investigación bastante amplia a fin de ofrecer elementos en torno a su relevancia como objeto de estudio, el conocimiento del rol de los medios de comunicación en el proceso de política pública sigue siendo ambiguo y limitado. Sin embargo, se ha establecido que éstos juegan un papel importante en las políticas públicas y se ha logrado determinar que ejercen cierta influencia a través de algunos subcampos de estudio, como el establecimiento de la agenda pública o agenda setting (McCombs y Shaw, 1972). Asimismo, se ha logrado establecer que los atributos y características propias de las políticas transmiten información y compiten por la atención del público, las élites y los medios de comunicación. En este sentido, el establecimiento de la agenda desde el enfoque de los procesos de política se basa fundamentalmente en la atención mediática de las políticas y de las dinámicas de las mismas en el nivel del sistema político (Wolfe, Jones y Baumgartner, 2013).

Esta influencia de los medios en las políticas públicas es mucho más visible en las etapas primarias del proceso de políticas, cuando se inicia el establecimiento de la agenda (Kingdon, 1984; Baumgartner y Jones, 1993; Wolfe, Jones y Baumgartner, 2013). Sin embargo, también tienen efecto en distintas etapas del proceso en la medida en que contribuyen a fijar la atención mediática en actores diversos y en distintos temas de política en tiempos determinados (Wolfe, 2012).

Así, para comprender el papel de los medios de comunicación dentro del proceso de políticas se recurre a la visión del establecimiento de la agenda (agenda setting) y de atención de los medios (media attention). En esta línea, Boydstun (2013) realizó un estudio que explica cómo los medios de comunicación moldean la atención pública hacia ciertos temas. Esta autora plantea que el efecto de los medios no es constante, sino, más bien, episódico e irregular, ya que pone la aten- 
ción en algunos temas pero ignora otros. Por lo tanto, los medios funcionan de manera similar a como ocurre en el proceso de políticas: de forma dinámica.

Gran parte de los estudios que intentan integrar teorías para comprender cómo funcionan los medios en el proceso de políticas buscan analizar cuál es el proceso de atención que brindan los medios a ciertos temas. Estos ciclos de atención pueden determinar el rumbo de las decisiones, orientar el discurso, generar cambios en la opinión pública y tener consecuencias directas en el público, es decir, generar efectos importantes en la opinión pública. El trabajo clásico de Downs (1972a) sobre el "ciclo de atención" de los temas públicos postula que las cuestiones políticas se mueven de forma cíclica dentro de la conciencia pública y que estas cuestiones se desplazan gradualmente dentro de periodos de baja a alta importancia. En este sentido, el público puede pasar de un "entusiasmo eufórico" a un declive gradual en el interés en los asuntos públicos. En la opinión de Downs, los medios de comunicación resultan fundamentales al afectar la importancia otorgada a ciertos temas.

Dentro de la visión más tradicional de la relación entre medios y políticas públicas se ha establecido que los medios tienen la función de moldear la agenda pública, aunque también se argumenta que su papel principal es proveer información a los ciudadanos para orientar las decisiones políticas (Strömberg, 2001). Se asume que los medios proveen información a los ciudadanos acerca de las políticas y que los hacedores de políticas públicas ponen atención a los medios como una forma de monitorear el ambiente político en el que se encuentran. Sin embargo, son las élites políticas las que alimentan en gran medida los insumos que los medios utilizan para informar a los ciudadanos. Koch-Baumgarten y Voltmer (2010) establecieron que el vínculo más claro entre medios y política pública es la opinión pública. Los políticos ven la agenda de los medios como un atajo hacia la opinión pública, en la medida en que asumen que los medios ejercen cierta influencia sobre los ciudadanos.

La atención que brindan los medios a ciertos sucesos se ha operacionalizado como la cobertura mediática que recibe un determinado tema, ya sea en periódicos o en televisión, aunque hay una cantidad considerable de estudios que analizan la cobertura mediática en la prensa escrita, principalmente por la accesibilidad de los datos. Esta cobertura, medida únicamente como cantidad de notas que recibe un tema específico, se ha sofisticado con el paso del tiempo y se ha regido bajo los marcos de teorías, como la teoría del establecimiento periodístico de temas (McCombs y Shaw, 1972, 1993; McCombs, Shaw y Weaver, 1997; McCombs y Reynolds, 2002; McCombs, 2004). 
La teoría de agenda setting plantea que hay una fuerte correlación entre el énfasis que los medios ponen en ciertos temas y la importancia que las audiencias atribuyen a dichos temas (McCombs y Shaw, 1972). Se asume que la gente forma opiniones en función de la información más accesible y después toma decisiones en función de ésta. En estricto sentido, esta teoría plantea que no es la información del tema la que produce el efecto, sino el hecho de que ese tema ha recibido determinada atención. Desde sus inicios, esta teoría ha generado una cantidad considerable de estudios que han intentado medir el efecto de agenda de los medios en las audiencias. ${ }^{3}$

La teoría de agenda setting surge como una teoría de efectos de los medios y tuvo un desarrollo notable en estudios de política pública. La teoría establece una distinción entre la agenda mediática y la agenda del público. Descansa sobre un supuesto de transferencia de relevancia, donde los medios posicionan determinados objetos que posteriormente adquieren relevancia para la audiencia. Para McCombs (2004) el establecimiento de agenda tiene consecuencias notables en el público. La agenda mediática transfiere la relevancia del objeto, que en la agenda del público desencadena una serie de procesos que van desde la formación de opinión, la dirección e intensidad de las opiniones y el comportamiento. Si bien es cierto que cuando hablamos de agenda setting hablamos de la hipótesis central de esta teoría, donde la cobertura tiene repercusión en la importancia pública atribuida a ciertos temas, esta perspectiva ha evolucionado hacia otros frentes, analizando las distintas consecuencias que tiene la cobertura mediática en diversos procesos políticos. ${ }^{4}$

Con el paso del tiempo, el término atención mediática (media attention) se ha conceptualizado en la cantidad y prominencia de la cobertura de un actor, evento o tema generando diversas medidas e índices para producir predicciones acerca de las motivaciones de un determinado medio para cubrir con mayor frecuencia un tema que otro (Atkinson, Lovett y Baumgartner, 2014). Este enfoque está relacionado más con la cantidad de artículos que genera un tema que con el contenido de los mismos, lo cual se define también como cobertura me-

\footnotetext{
${ }^{3}$ En un artículo titulado "La anatomía de la investigación en agenda setting", Rogers, Dearing y Bregman (1993) identificaron más de 200 artículos científicos generados bajo el marco de esta teoría después de la publicación del artículo de McCombs y Shaw en 1972.

${ }^{4} \mathrm{La}$ extensa literatura en este tema ha sugerido que los medios tienen una función importante al determinar qué temas son importantes tanto para el público como para los hacedores de políticas públicas. Entonces, el establecimiento de la agenda es una de las aristas en la que se tiene más certeza acerca del funcionamiento de la relación entre medios y política pública.
} 
diática. En esta línea, Mazur (2009) argumenta que la cobertura es más importante que el contenido en términos de la influencia sobre las audiencias.

Los estudios de agenda setting han intentado mostrar las relaciones entre los medios, el público y los hacedores de políticas públicas y, al hacerlo, han mostrado que estas relaciones pueden variar o ser bidireccionales. Sin embargo, la evidencia empírica no ha sido concluyente en este aspecto. Soroka (2002) intentó traducir empíricamente este complejo entramado de relaciones y demuestra que diferentes temas de política pueden traducirse en distintas dinámicas de agenda setting. Los medios a veces lideran la agenda y a veces la siguen. Además, demuestra que el efecto de los medios en el público varía a partir de la naturaleza y complejidad de los temas de política. En este sentido, Robinson (2000) plantea que la incertidumbre política y el consenso por parte de las élites son variables que intervienen e impactan en la habilidad de los medios para cambiar el curso de las políticas públicas. Lo anterior es consistente con lo encontrado por Wolfe (2012), quien demuestra que la atención de los medios es fundamental en el proceso de políticas, pero no así en el resultado final de políticas concretas.

Entre los estudios que tratan el impacto de los medios sobre las élites, destacan los artículos que han planteado que la cobertura mediática de los sucesos políticos afecta la prominencia otorgada a dichos sucesos por los gobernantes, legisladores y partidos políticos (Walgrave y Van Aelst, 2006). Lo anterior está determinado porque los medios de comunicación ofrecen información a las élites y éstas pueden obtener ganancias del clima de opinión generado por los medios de comunicación para promoverse a sí mismos o sus políticas (Walgrave y Van Aelst, 2006). En esta misma línea se ha demostrado también que las élites reaccionan a la opinión pública (Erikson, Wright y Mclver, 1993; Page y Shapiro, 1983; Burstein, 2003). Por ejemplo, Burstein (2003) encontró a través de una revisión sistemática de la literatura sobre el impacto de la opinión pública sobre la política pública, que la opinión pública tiene un efecto en las decisiones de política y que cuanto más importante o prominente es el tema para los ciudadanos, la relación es más fuerte. Esto es consistente con la teoría de agenda setting, que demuestra que los medios de comunicación tienen un efecto en la opinión pública, específicamente en la prominencia que los ciudadanos otorgan a ciertos temas (McCombs y Shaw, 1972, 1993; McCombs, Shaw y Weaver, 1997; McCombs y Reynolds, 2002; McCombs, 2004).

Toda esta literatura sobre la importancia de los medios de comunicación ha descansado en una serie de supuestos sobre su función social, tales como la función de educar a la ciudadanía, de moldear la opinión pública, de motivar a las 
élites a tomar decisiones, entre otras. Para McCombs (2004) la comunicación de masas tiene tres funciones importantes: la obtención de un entorno de mayor alcance, lograr el consenso entre los sectores de la sociedad y la transmisión de la cultura. Entonces, podemos establecer que la agenda pública, los grupos de interés y las élites impactan a los medios y los medios impactan también la agenda política de las propias élites.

Así, el establecimiento de la agenda desde el enfoque de los procesos de políticas se basa fundamentalmente en las dinámicas de atención en torno a las decisiones que se toman en el sistema político. Las imágenes, los marcos y los atributos de las políticas transmiten información y compiten por la atención del público, la élite y los medios de comunicación (Wolfe, Jones y Baumgartner, 2013). Derivado de lo anterior, la complejidad en el entramado de relaciones que se generan en los procesos de políticas y las dinámicas de atención mediática han propiciado que el estudio de los medios en estos procesos se vuelva fundamental. Como se mencionó antes, tanto la teoría de agenda setting como la perspectiva de media attention funcionan de manera conjunta para explicar cómo los medios de comunicación pueden contribuir a orientar el rumbo de una política específica en cada una de las diversas fases del proceso de política.

Se ha demostrado que los medios de comunicación pueden cambiar la definición o la imagen que se tiene sobre un tema (Baumgartner y Jones, 1993). Una de las aproximaciones teóricas que se han utilizado para comprender mejor este fenómeno intenta responder a cómo son presentadas estas imágenes de las políticas. Para ello se requiere una conceptualización distinta. La teoría del framing (Pan y Kosicki, 1993; 2001; Goffman, 1974; Tuchman, 1978; Gitlin, 1980; Tversky y Kahneman, 1981, 1986; Gamson y Modigliani, 1987, 1989; Entman, 1991, 1993) también ha intentado posicionar la atención que brindan los medios a los sucesos políticos como una variable importante para los temas públicos y hace referencia a "cómo" un tema es presentado en los medios y su efecto en las audiencias. Este término tiene orígenes psicológicos (Pan y Kosicki, 1993; Tversky y Kahneman, 1981, 1986) y sociológicos (Goffman, 1974).

Se puede advertir que toda la investigación que ha intentado explorar los efectos de los medios de comunicación en las políticas públicas no ha proporcionado evidencia concluyente sobre una relación lineal medios-políticas. Sin embargo, el debate continúa sobre todo porque la agenda política está conformada por una serie de temas a los que los actores políticos enfocan su atención, por lo cual la consideración de la agenda es una condición necesaria, especialmente para las decisiones políticas. 


\section{EL PACTO POR MÉXICO: EL FACILITADOR DE LOS CAMBIOS CONSTITUCIONALES}

Desde su inicio el primero de diciembre de 2012, el discurso del titular del Ejecutivo Federal mexicano (2012-2018) estuvo en buena medida dedicado a comunicar su estrategia política para construir un gobierno eficaz que lograra significativamente mejores resultados de política pública, sin que se viera trastocada la gobernabilidad del país. Esta estrategia de cambio se elaboró en torno a cinco ejes de logros a alcanzar, trece decisiones presidenciales y 95 compromisos articulados en cinco acuerdos; de estos últimos, nueve corresponden a la procuración de un acceso social equitativo a una educación de calidad (Del Castillo, 2013).

De esos cinco ejes destaca el relativo a la educación, que a la letra dice: "Lograr un México con educación de calidad para todos" (Peña Nieto, 2012: 8) y entre las trece decisiones presidenciales está el impulso de una RE a partir del reconocimiento de que "el capital humano es la base del desarrollo y el progreso de un país: ésta es la razón por la que corresponde al Estado la rectoría de la política educativa” (Peńa Nieto, 2012: 13). El instrumento político central de esta estrategia de cambio fue el Pacto por México, que expresó la pretensión del nuevo gobierno federal para lograr en el corto plazo cambios políticos que favorecieran decisiones de política pública que aseguraran resultados e impactos claramente visibles para los ciudadanos.

La RE de 2012 fue producto de un pacto político entre fuerzas partidarias con presencia en el Congreso Federal, donde se dejó fuera a un actor que había ocupado tradicionalmente un lugar central en los procesos decisionales de política educativa: el Sindicato Nacional de Trabajadores de la Educación (sNTE). Por ello el rechazo de su presidenta, Elba Esther Gordillo, a la RE en general, ${ }^{5}$ especialmente al cambio no incremental en la regulación del ingreso y la permanencia del magisterio en servicio, implicados en las reformas a los artículos $3^{\circ}$ y 73 de la Constitución de los Estados Unidos Mexicanos, la reforma de la Ley General de Educación, la nueva Ley del Servicio Profesional Docente y la Ley del Instituto Nacional de Evaluación Educativa.

\footnotetext{
${ }^{5}$ El primer signo de resistencia se dio en el marco del VI Congreso Nacional Extraordinario del sNTE (octubre de 2012) durante el cual se vislumbró un claro posicionamiento del SNTE ante posibles cambios de política educativa con implicaciones laborales de gran envergadura. Algunas expresiones de Elba Esther Gordillo dan cuenta de lo anterior: "Haremos respetar nuestra autonomía e independencia sindical a pulso"; "Revisemos la relación con los partidos, revisemos la relación con el gobierno [...] perdón ayer me necesitaste al gremio y hoy me rechazas, la historia los juzgará, nosotros vamos por el futuro" (Áviles y Solís, 2012) y finalmente "No estamos a la venta, estamos en pie de lucha, por la dignidad de los maestros de México" (Poy, 2012).
} 
La RE implicó cambios no incrementales fundamentales y un conjunto de cambios incrementales. ${ }^{6}$ El cambio no incremental que trastocó derechos laborales del magisterio en servicio explica en buena parte tanto el conflicto político Gobierno Federal-Coordinadora Nacional de Trabajadores de la Educación (CNTE), que paralizó la RE durante 2013-2015, como el tamaño y rasgos de la cobertura mediática que recibió la RE, ya que eso nunca antes se había producido en el sistema educativo mexicano desde la creación de la Secretaría de Educación Pública en 1921.

A la distancia, es posible afirmar que el Pacto por México que dio a luz la primera reforma del gobierno federal (2012-2018), la RE, en tan sólo veinte días de gobierno ${ }^{7}$ fue un acuerdo político que duró al menos el tiempo necesario para la reforma de los artículos $3^{\circ}$ y 73 constitucionales y la aprobación de las tres leyes secundarias (la Ley General de Educación, la Ley del Instituto Nacional para la Evaluación de la Educación, INEe y la Ley del Servicio Profesional Docente, SPD), a lo cual siguió el resquebrajamiento del Pacto al no haber acuerdos principalmente en torno al papel asignado a la evaluación docente y a la regulación de la permanencia de los docentes en servicio.

Después de la fractura e incluso desdibujamiento del Pacto por México a raíz de la RE, lo que siguió como parte de la estrategia política para evitar a toda costa la mencionada paralización y postergación de la reforma, fue recurrir a la Conferencia Nacional de Gobernadores (Conago), a fin de reposicionar la RE bajo el mandato del nuevo secretario de Educación, Aurelio Nuño. Así, en el marco de la Conago, que tuvo lugar el 19 octubre de 2015, el nuevo secretario logró posicionar la agenda de la RE a través de la Comisión Ejecutiva de Educación, reunión en la cual, con la presencia del titular del Ejecutivo Federal y los 31 gobernadores, se acordó un nuevo esquema de coordinación que buscó establecer una mejor comunicación entre la federación y los sistemas educativos estatales y

\footnotetext{
${ }^{6}$ Los cambios "no incrementales" (Dente y Subirats, 2014), son aquellos que liderados por sujetos considerados como innovadores de políticas públicas (Mintrom y Norman, 2009), logran desafiar viejas pautas decisionales del pasado que durante años han frenado dinámicas de cambio de más largo aliento bajo condiciones contextuales específicas. Siguiendo el planteamiento original de Lindblom (1979), se asume en esta ejemplificación que un cambio de políticas (incremental y no incremental) responde en gran parte a la convergencia de acuerdos y consensos entre distintos actores participantes en un proceso de políticas públicas (policy process) que busca resolver un problema público específico. Esto es, el cambio de políticas es resultado de la interacción político-social más que de un acto de voluntad de un decisor aislado (Dente y Subirats, 2014: 59), particularmente cuando está en cuestión la solución de un problema complejo (wicked problem) como, en este caso, transformar los aprendizajes de los estudiantes de educación básica en México.

${ }^{7}$ El presidente Enrique Peńa Nieto tomó posesión de su cargo el primero de diciembre de 2012 y el 20 de diciembre del mismo año se recibió en la Cámara de Diputados del Congreso de la Unión el decreto de reforma de los artículo $3^{\circ}$ y 73 constitucionales, lo cual representó el inicio de un conjunto de decisiones y acciones que dieron luz a nuevas leyes secundarias de política educativa y de programas.
} 
el establecimiento del seguimiento del proceso de implementación de la reforma a partir de la división del país en cinco regiones educativas (noreste, noroeste, centro, occidente y sur-sureste).

En suma, la estrategia del gobierno federal mexicano para acelerar los cambios constitucionales indispensables para la RE, contempló básicamente dos decisiones políticas centrales: primero, la construcción y formalización del Pacto por México en 2012-2013 y, segundo, llevar la agenda de la RE a la Conago en 2015, habiendo logrado impedir que el conflicto político Gobierno Federal-CNTE detuviera la implementación de la RE (aplicación de la evaluación docente). La relevancia de ambas consiste en que rompieron con el patrón político de cambios de 1992 en el Acuerdo Nacional para la Modernizacion de la Educacion Basica (ANMEB). Esto es, trastocaron la lógica política con la que se habían tomado las decisiones de política pública educativa en las dos décadas anteriores.

\section{LOS CAMBIOS DE POLÍTICA EDUCATIVA}

En tanto proceso político-técnico, la RE tiene dos aspectos: a) la decisión política del gobierno federal mexicano para mejorar en el mediano y largo plazos la calidad y equidad del servicio educativo, cuya "decisión madre" es impulsar la $\mathrm{RE}, \mathrm{y} b$ ) el proceso secuencial de decisiones de política pública específica y acciones orientadas a generar una ruta de cambio para mejorar la calidad y equidad educativas. $^{8}$

En este proceso se articularon distintos tipos de decisiones de política pública: de corte constitucional y legal, de políticas públicas específicas y de programas. Las primeras tienen que ver con la reforma a los artículos $3^{\circ}$ y 73 de la Constitución de los Estados Unidos Mexicanos; las legales, con la actualización o creación de leyes secundarias (Ley General de Educación, Ley General del Servicio Profesional Docente, Ley del Instituto Nacional para la Evaluación de la Educación); las de política pública específica, con la del Servicio Profesional Docente (SPD) y la Política Nacional de Evaluación para la Educación (PNEE), y las de programas, como es el caso del Programa de Promoción en la Función por Incentivos en la Educación Básica. Las dos primeras representan el diseño de la

\footnotetext{
${ }^{8}$ Las decisiones de política pública general son elecciones de rumbo ante determinados problemas públicos que efectúa el gobernante entre alternativas. Las decisiones de política pública específica son también elecciones entre alternativas pero respecto a determinados aspectos de un problema público. Las acciones son, a su vez, producto de conjuntos de decisiones de menor alcance orientadas a encontrar la forma de ejecutar las decisiones de política pública general y específicas, aquí para mejorar la calidad y equidad educativas. Por ello es común que se traten como sinónimos y de ahí la relevancia de distinguir entre ellas (Véase Majone, 1992).
} 
reforma, en tanto que las decisiones de política específica y de programas forman parte del proceso de implementación.

La RE es el proyecto de transformación estructural más importante del Sistema Educativo mexicano desde el ANMEB de 1992. Este año representó un punto de inflexión. Su propósito político, desde sus orígenes, fue asegurar intereses cupulares del SNTE y mantener control sobre aspectos estratégicos para el mejoramiento de la calidad. Por esta vía, fue posible impulsar reformas en algunas políticas para responder a tendencias de cambio internacionales, sin que esto trastocara intereses y privilegios políticos y laborales adquiridos por parte del actor sindical (Del Castillo, 2012: 644). Entre los principales privilegios obtenidos destacan mantener el criterio de antigüedad como único para permanecer en el servicio educativo, acceder de forma automática a una plaza al egresar de los estudios normalistas, participar en los procesos de evaluación docente a través de las Comisiones Mixtas y presentarse de forma voluntaria en los procesos de evaluación.

La adquisición de un conjunto de derechos políticos se convirtió en uno de los grandes aciertos del ANMEB, desde la perspectiva de la gobernabilidad del sistema educativo. A veinte años de distancia, la RE trastoca y desafía precisamente esas conquistas político-administrativas, desafía derechos político-laborales. Así, en ocasiones la RE es considerada más una reforma político-laboral (Arnaut, 2013) que una reforma educativa. Desde nuestra perspectiva, es una reforma política para transformar las políticas educativas (Del Castillo, 2013).

En línea con los cambios constitucionales (artículos $3^{\circ}$ y 73 ), que establecieron como derecho el acceso a una educación de calidad para todos los mexicanos y para materializar éste, se modificó la Ley General de Educación (LGE) y se crearon la Ley del Instituto Nacional de Evaluación Educativa (LINEE) y la Ley del Servicio Profesional Docente (LSPD), ambas publicadas el 11 de septiembre de 2013.

El nuevo andamiaje legal fue producto de decisiones de política pública general de largo alcance buscando cambios no incrementales que son el horizonte de la RE. Estas decisiones han sido: a) recuperar la rectoría del Estado en los temas de política educativa, lo cual implicó que el impulso inicial de la RE se organizara en torno al Pacto por México, con lo que se trastocó el poder de veto del SNTE y se evitó la incidencia de su dirigencia vitalicia (Elba Esther Gordillo); b) regular el ingreso, promoción, desempeño y permanencia de los maestros mediante la creación del Servicio Profesional Docente, con implicaciones muy importantes en los derechos laborales previamente adquiridos con la firma del ANMEB y en la creación de un nuevo sistema de incentivos (Programa de Promoción en la Función por Incentivos en la Educación Básica), y c) otorgarle a la evaluación una centra- 
lidad estratégica asociada al SPD para lo cual se suma una decisión más de la mayor trascendencia: otorgarle autonomía al Instituto Nacional para la Evaluación de la Educación (INEE), hoy responsable del Sistema Nacional de Evaluación Educativa (SNEE) y por consiguiente de la Política Nacional de Evaluación Educativa.

La nueva centralidad de la evaluación dio lugar a cambios estratégicos nunca antes vistos en el sistema educativo mexicano. Por primera vez, la responsabilidad del logro educativo, entendido como el mejoramiento en los aprendizajes, la comparten la Secretaría de Educación Pública (SEP) y el INEE, lo cual representa un desafío de coordinación política interinstitucional. Destacan la autonomía del INEE, sustentada en la ley secundaria que lleva el mismo nombre; y la creación del SNEE bajo la responsabilidad del INEE, cuyo objetivo es la articulación de los distintos elementos que convergen en los propósitos de la PNEE. Esta política cobra vida a nivel nacional a través del diseño e instrumentación del Programa Estatal de Evaluación y Mejora Educativa (PEEME) en cada entidad federativa, para que genere su propia información de cara a la toma de decisiones orientada a la mejora educativa.

Como instrumento de política pública educativa, la evaluación toma vida con la creación del SPD. La regulación del ingreso, promoción, reconocimiento y permanencia, articulada a la evaluación, trastoca los patrones tradicionales. A través de la evaluación se busca reconocer el mérito en la trayectoria de los docentes en servicio y decidir el ingreso de los mismos al sistema educativo.

Este conjunto de decisiones de política pública educativa tiene lugar en el marco del cambio constitucional más amplio mencionado, cuyo propósito fue establecer el acceso a una educación de calidad como derecho. Asimismo, estas decisiones producen transformaciones que son cambios incrementales: ${ }^{9}$ un sistema de información y gestión educativa (Siged) a partir de un censo de maestros, escuelas y alumnos, funcional al mejoramiento de la eficiencia de la gestión y comunicación del sistema educativo; el fortalecimiento de la autonomía de gestión de las escuelas, para que construyan estrategias propias para la resolución de problemas en el marco de cada una; el establecimiento de Escuelas de Tiempo Completo, para un uso eficiente del tiempo y el desarrollo académico; la creación de un programa de computadoras portátiles con conectividad; el fortalecimiento de la educación inicial de los maestros, mediante su profesionalización; el

\footnotetext{
${ }^{9}$ Charles Lindblom considera que el incrementalismo es un patrón de comportamiento político, ya que difícilmente es posible generar desde la toma de decisiones cambios radicales. El cambio incremental es aquel que ocurre de forma gradual a través de pasos pequeños o grandes pero en una misma línea continua (Lindblom, 1979).
} 
incremento de la cobertura de la educación media superior y superior, asegurando recursos presupuestales, y la creación de un programa nacional de becas.

\section{MÉTODO}

Para describir y analizar la cobertura de la RE se utilizó el concepto de atención mediática. Este concepto comprende dos dimensiones: el número de notas periodísticas que recibió la RE entre 2012 y 2015 y la relevancia que le otorgó la prensa a ciertos temas y actores de la misma. Se analizaron 6213 notas publicadas en El Universal, Reforma, El Financiero y La Jornada desde el primero de diciembre de 2012 al 31 de diciembre de 2015, que corresponden a un total de 37 meses de cobertura que coinciden con la aprobación de la iniciativa de decreto que reforma la Constitución, con el diseńo normativo de la política educativa y con el proceso de implementación de la RE.

La elección de las fuentes periodísticas respondió al tiraje y la circulación nacional de los periódicos. El Universal, Reforma y La Jornada son los tres periódicos nacionales con mayor tiraje en México, de acuerdo con el Padrón Nacional de Medios Impresos, de la Dirección General de Medios Impresos de la Secretaría de Gobernación. ${ }^{10}$ Para la elección de la cuarta fuente se tomó uno de los que siguen en cobertura: Milenio, Excélsior y El Financiero. Se eligió el periódico El Financiero debido a que se ha caracterizado por su interés periodístico en la cobertura de temas educativos. Las notas de El Universal, Reforma y El Financiero se extrajeron de la base de datos Msi Emerging Markets, que condensa notas de distintos periódicos nacionales e internacionales y, para el caso de La Jornada, las notas se extrajeron directamente del portal de internet del periódico. La selección de las notas se realizó en función de que contuvieran las palabras "reforma educativa" en encabezados o cuerpo de la nota.

Se construyó una base de datos original donde se analizaron 19 variables que se describen en el cuadro 1. Estas variables fueron codificadas en términos de ausencia o presencia del atributo en cada nota. Las variables 1 y 2 (fecha y medio) son para identificación de la nota. La variable 3 denominada "tipo de nota" se utilizó como una variable de filtro que permitió elegir aquellas notas cuyo contenido global se refiere específicamente a la reforma educativa. Dado que se utilizó un buscador de noticias, se utilizó el término "reforma educativa" para obtener la totalidad de las notas, sin embargo, se encontraron un buen número de notas

${ }^{10}$ El Universal tiene un tiraje de 180000 ejemplares; el periódico Reforma, de 140000 y La Jornada cuenta con un tiraje de 107666 ejemplares. Éstos son los tres periódicos nacionales con mayor tiraje. 
CUADRO 1. Variables analizadas

\begin{tabular}{|c|c|c|}
\hline Variable & Descripción & Codificación \\
\hline 1. Fecha & Se captura la fecha exacta de la nota & $\begin{array}{l}\text { Fecha exacta de } \\
\text { la nota }\end{array}$ \\
\hline 2. Medio & ¿Qué medio es? & $\begin{array}{l}1=\text { El Universal } \\
2=\text { Reforma } \\
3=\text { El Financiero } \\
4=\text { La Jornada }\end{array}$ \\
\hline 3. Tipo de nota & $\begin{array}{l}\text { Esta variable permite filtrar las notas cuyo interés principal } \\
\text { es cubrir la reforma educativa }\end{array}$ & $\begin{array}{l}1=\text { Mención } \\
\text { central } \\
2=\text { Mención } \\
\text { secundaria }\end{array}$ \\
\hline 4. Rectoría del Estado & $\begin{array}{l}\text { La nota contiene una mención específica a la rectoría del } \\
\text { Estado }\end{array}$ & $0=\mathrm{No} ; 1=\mathrm{Sí}$ \\
\hline 5. Reforma artículo tercero & $\begin{array}{l}\text { La nota contiene una mención específica a la reforma al } \\
\text { artículo tercero constitucional }\end{array}$ & $0=\mathrm{No} ; 1=\mathrm{Sí}$ \\
\hline $\begin{array}{l}\text { 6. Servicio Profesional } \\
\text { Docente }\end{array}$ & $\begin{array}{l}\text { La nota contiene una mención específica al servicio } \\
\text { profesional docente: regulación del ingreso, promoción, } \\
\text { reconocimiento y permanencia. Plazas, ascensos e ingreso }\end{array}$ & $0=\mathrm{No} ; 1=\mathrm{Sí}$ \\
\hline $\begin{array}{l}\text { 7. Sistema Nacional } \\
\text { de Evaluación }\end{array}$ & $\begin{array}{l}\text { La nota contiene una mención específica a la evaluación del } \\
\text { sistema y del desempeño docente y de las políticas }\end{array}$ & $0=\mathrm{No} ; 1=\mathrm{Sí}$ \\
\hline $\begin{array}{l}\text { 8. Instituto Nacional para } \\
\text { la Evaluación de la } \\
\text { Educación (INEE) }\end{array}$ & $\begin{array}{l}\text { La nota contiene una mención específica al INEE (autonomía, } \\
\text { junta de gobierno) }\end{array}$ & $0=$ No; $1=$ Sí \\
\hline 9. Evaluación docente & $\begin{array}{l}\text { La nota contiene una mención específica a la evaluación } \\
\text { docente }\end{array}$ & $0=\mathrm{No} ; 1=\mathrm{Sí}$ \\
\hline 10. Evaluación Educativa & $\begin{array}{l}\text { La nota contiene una mención específica a la evaluación de } \\
\text { la educación }\end{array}$ & $0=\mathrm{No} ; 1=\mathrm{Sí}$ \\
\hline $\begin{array}{l}\text { 11. Sistema de Información } \\
\text { y Gestión Educativa } \\
\text { (Siged) }\end{array}$ & $\begin{array}{l}\text { La nota contiene una mención específica al sistema de } \\
\text { información y gestión educativa (Siged) }\end{array}$ & $0=$ No; $1=$ Sí \\
\hline 12. Censo educativo & $\begin{array}{l}\text { La nota contiene una mención específica al censo } \\
\text { de escuelas, maestros y alumnos de educación básica }\end{array}$ & $0=\mathrm{No} ; 1=\mathrm{Sí}$ \\
\hline $\begin{array}{l}\text { 13. Autonomía de la gestión } \\
\text { escolar }\end{array}$ & $\begin{array}{l}\text { La nota contiene una mención específica a la autonomía de } \\
\text { las escuelas o de la gestión escolar }\end{array}$ & $0=$ No; 1 = Sí \\
\hline 14. Infraestructura escolar & $\begin{array}{l}\text { La nota contiene una mención específica a lainfraestructura } \\
\text { escolar }\end{array}$ & $0=\mathrm{No} ; 1=\mathrm{Sí}$ \\
\hline 15. Modelo educativo & $\begin{array}{l}\text { La nota contiene una mención específica a la revisión del } \\
\text { modelo educativo y como parte de ésta a los materiales y } \\
\text { métodos educativos }\end{array}$ & $0=$ No; 1 = Sí \\
\hline 16. Idoneidad docente & $\begin{array}{l}\text { La nota contiene una mención específica a la idoneidad } \\
\text { docente como el criterio que mide conocimientos y } \\
\text { habilidades en docentes y directivos }\end{array}$ & $0=$ No; $1=$ Sí \\
\hline
\end{tabular}


CUADRO 1. Variables analizadas (continuación)

\begin{tabular}{|c|c|c|}
\hline Variable & Descripción & Codificación \\
\hline $\begin{array}{l}\text { 17. Escuelas de tiempo } \\
\text { completo }\end{array}$ & $\begin{array}{l}\text { La nota contiene una mención específica al establecimiento } \\
\text { de escuelas de tiempo completo }\end{array}$ & $0=$ No; 1 = Sí \\
\hline 18. Prohibición alimentos & $\begin{array}{l}\text { La nota contiene una mención específica a la prohibición } \\
\text { de alimentos no saludables para los alumnos (alimentos } \\
\text { "chatarra") }\end{array}$ & $0=$ No; 1 = Sí \\
\hline 19. Calidad educativa & $\begin{array}{l}\text { La nota contiene una mención específica a la calidad de la } \\
\text { educación, es decir, si la reforma tendrá implicaciones en la } \\
\text { calidad de la educación }\end{array}$ & $0=$ No; 1 = Sí \\
\hline 20. Calidad como derecho & $\begin{array}{l}\text { La nota contiene una mención específica a la calidad de la } \\
\text { educación como derecho y por lo tanto obligación } \\
\text { del Estado }\end{array}$ & $0=$ No; $1=$ Sí \\
\hline 21. Aprendizaje & $\begin{array}{l}\text { La nota contiene una mención específica a las implicaciones } \\
\text { que tendrá la reforma en el aprendizaje de los alumnos y } \\
\text { alumnas }\end{array}$ & $0=$ No; 1 = Sí \\
\hline 22. Equidad & $\begin{array}{l}\text { La nota contiene una mención específica a las implicaciones } \\
\text { que tendrá la reforma en la equidad (acceso) }\end{array}$ & $0=$ No; $1=$ Sí \\
\hline 23. Actor & $\begin{array}{l}\text { Se captura el actor principal de la nota. Ejemplo: Enrique } \\
\text { Peña Nieto, Emilio Chiayffet, etcétera }\end{array}$ & \\
\hline 24. Cargo del actor & $\begin{array}{l}\text { Se captura el cargo que desempeña el actor principal de } \\
\text { la nota. Ejemplo: presidente de la República, secretario de } \\
\text { Educación, etcétera }\end{array}$ & \\
\hline 25. Tono de la nota & En esta variable se codifica el posicionamiento de la nota & $\begin{array}{l}1 \text { = A favor } \\
2=\text { Neutro; } \\
3=\text { Crítico; } \\
4=\text { En contra }\end{array}$ \\
\hline
\end{tabular}

Fuente: Elaboración propia.

que contenían alguna mención a la reforma educativa en el marco de otros temas, por ejemplo, cuando se hablaba de un paquete de reformas, incluida la educativa. Estas notas no entraron en el análisis, dado que la cobertura de la reforma educativa no era el interés principal.

Todas las demás variables que se presentan en el cuadro 1 corresponden a los temas que están presentes en los distintos documentos de la reforma educativa: el decreto de reforma a los artículo $3^{\circ}$ y 73 constitucionales y las leyes secundarias: Ley General de Educación (LGE), Ley del Instituto Nacional de Evaluación Educativa (LINEE) y Ley General del Servicio Profesional Docente (LGSPD). Se revisaron los principales documentos de la reforma y se extrajeron los temas centrales y que fueron objeto de cambio. Además, se codificaron los actores gubernamentales y no gubernamentales que aparecieron como protagonistas de las notas (cuadro 1). 
Es importante mencionar que para contar con un mayor grado de objetividad, se trabajó con los temas establecidos en las leyes, tal como fueron nombrados. No es objetivo de este artículo realizar una discusión sobre estilos periodísticos con los que se cubren ciertos temas.

En la variable 25, que refiere al tono, se codifica el posicionamiento de la nota. Se decidió utilizar cuatro categorías: a favor, neutro, crítico o en contra. Esto se acordó en función de varios artículos que han propuesto estrategias de medición del tono en los medios de comunicación (Collins et al., 2006; Hopmann et al., 2010).

Con relación a las notas a favor, fue común encontrar que los actores gubernamentales promovieron la reforma educativa enalteciendo sus fortalezas y los cambios positivos que generaría en el sistema educativo mexicano. Asimismo, en algunas notas se mencionaba la palabra respaldo o respaldar en la emisión de declaraciones públicas. La categoría neutro se refiere a aquellas notas que sí tenían como mención central la reforma educativa, pero cubrían aspectos generales sin tener un posicionamiento. En este tipo de codificación también entraron las notas donde se cubrían las actividades de algún actor secundario a la reforma, por ejemplo: cuando la suprema corte acotó alguna solicitud, la cobertura concreta de acciones que se enmarcaban dentro de la reforma, entre otras.

Las notas codificadas dentro de la categoría crítico se refieren a situaciones en las que no existe un posicionamiento claro a favor o en contra, pero se destacan ciertas debilidades u oportunidades de mejora en la reforma educativa. Estas notas generalmente tienen como actor principal a la sociedad civil o a ciertos actores políticos que no están relacionados directamente con la reforma. Por último, las notas en contra contenían una oposición clara a la reforma. En estas notas aparecían frases como: "etapa de resistencia en contra de la reforma", "se unieron para realizar acciones conjuntas en contra de la reforma educativa", "en rechazo a la evaluación que plantea la SEP”, entre otras.

La categoría de tono de la nota es la que representa un riesgo más amplio de subjetividad. El cuadro 2 muestra fragmentos de notas representativas que ilustran cuándo una nota se puede clasificar dentro de las cuatro categorías propuestas para medir el tono.

\section{LA COBERTURA MEDIÁTICA DE LA REFORMA EDUCATIVA}

El universo de notas analizadas fue de 6213: 1749 notas (28.15\%) de El Universal; 1907 (30.69\%) de Reforma; 599 (9.64\%) de El Financiero y, por último, 1958 (31.51\%) de La Jornada. Del total de registros (6213), 68 por ciento de 
las notas (4206) otorgan a la RE lo que denominamos "una mención central”; el resto se consideró como "mención secundaria" (32\%) y por lo tanto no fue objeto de análisis. De ese subconjunto de notas, cuyo rasgo es que focalizan su atención en al menos un tema de la RE, encontramos que dos de ellos, La Jornada y Reforma son los periódicos que mayor cobertura le dieron a la reforma, 31.5 y 30.7 por ciento, respectivamente. Le sigue en importancia El Universal (28.1\%).

Los meses en los que la RE recibió mayor cobertura fueron abril, agosto y septiembre de 2013 (meses 5, 9 y 10 en la gráfica 1), que coinciden con la aprobación de las tres leyes secundarias, la resistencia de la Coordinadora Nacional de Trabajadores de la Educación y el surgimiento del Movimiento Popular Guerrerense (MPG).

La cobertura se mantiene relativamente estable hasta el mes 31, en que se intensifica de nuevo y corresponde al periodo de mayo a diciembre de 2015, en el que se registraron acontecimientos políticos de relevancia nacional junto con decisiones políticas para favorecer la estabilidad y la implementación de la RE: el Comunicado 129 de la SEP, en el cual se informa la suspensión indefinida de la

GRÁFICA 1. Cobertura de la reforma educativa en cuatro periódicos nacionales

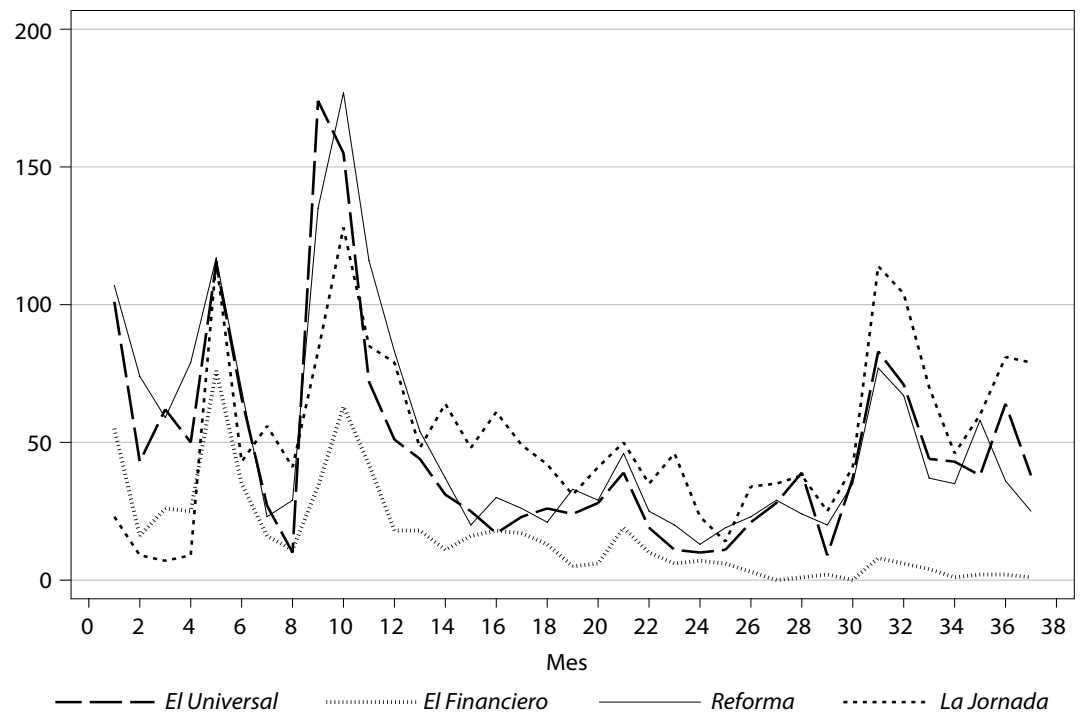

Fuente: Elaboración propia. 
GRÁFICA 2. Menciones centrales y menciones secundarias de la reforma educativa

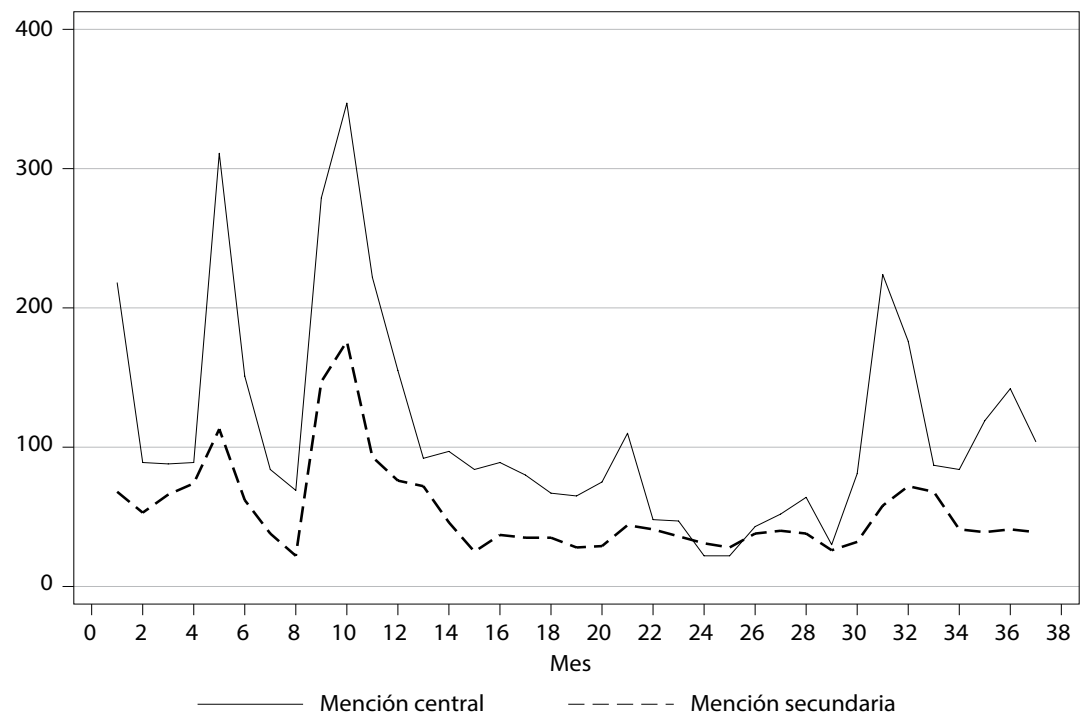

Fuente: Elaboración propia.

evaluación (29 de mayo), las elecciones intermedias ( 2 de julio), el nombramiento de Aurelio Nuño como secretario de Educación (27 de agosto), la resistencia de Oaxaca para armonizar la ley educativa estatal con la LGE y el desmantelamiento del Instituto Estatal de Educación Pública de Oaxaca (21 julio), la aplicación de ceses por no asistir a la evaluación diagnóstica (17 de octubre), la Conago Educativa (19 de octubre) y el despliegue de la policía para resguardar instalaciones federales para la segunda aplicación de la evaluación (22 de noviembre) (véase gráfica 1).

La tendencia entre menciones secundarias y menciones centrales sigue un mismo patrón de cobertura (gráfica 2).

El tono de las notas es una variable relevante para hacer visible el posicionamiento de los medios y las posiciones que han adoptado los distintos actores involucrados en los temas centrales. Esta variable toma cuatro posibles valores: a favor, neutro, crítico y en contra. El número de notas con una postura en contra de la reforma registran mayores niveles en abril de 2013 e incrementan entre agosto y octubre de 2013, periodo en el que se presentan las principales manifes- 
taciones de resistencia a la aprobación de las leyes secundarias. Después, el número de notas en contra disminuye hasta presentar un incremento durante el periodo comprendido entre junio y julio de 2015 , cuando se producen las decisiones y acciones políticas de alto impacto, como se detalló más arriba.

Se encontró que los posicionamientos dan lugar a un ambiente de polarización en la agenda política de los medios. En este sentido, se encontraron diferencias importantes por periódico. El cuadro 3 muestra que del total de notas del periódico El Universal, 56.3 por ciento fueron notas a favor y 25 por ciento en contra. Lo contrario sucede con La Jornada, donde los porcentajes se invierten (29.16\% de notas a favor y $54 \%$ en contra). Los periódicos Reforma y El Financiero man-

CUADRO 2. Ejemplos de codificación del tono de la nota

\begin{tabular}{ll}
\hline Categoria & Ejemplos \\
\hline A favor & Al respaldar la reforma educativa, el secretario de la Defensa Nacional (Sedena), Salvador Cienfuegos \\
Zepeda, sostuvo que la educación es el elemento central para el desarrollo del país. \\
- Por unanimidad, el pleno de la Suprema Corte de Justicia de la Nación avaló la constitucionalidad de las \\
normas y los artículos de la reforma educativa que hacen obligatoria la evaluación al magisterio. \\
- El secretario de Educación Pública, Aurelio Nuño, dijo que"a pesar de las barreras y resistencias que \\
existen contra la reforma educativa estamos venciendo para construir una educación de calidad en \\
favor de los jóvenes y los niños de México". \\
- La Suprema Corte de Justicia de la Nación acotó las pretensiones del magisterio disidente de evitar la \\
evaluación, al justificar el cese o reubicación de los maestros no aptos para estar al frente de un grupo \\
para impartir clases en educación básica. \\
- "Es importante mencionar que a partir del ciclo escolar 2015-2016, con recursos del programa de la \\
reforma educativa, se continuará de manera significativa con el programa Bebederos, destinando \\
mil 135 millones de pesos que permitirá incrementar la meta en más de 11 mil planteles educativos", \\
comentóVega Vargas. \\
- Esta prueba fue la primera evaluación correspondiente a la reforma educativa, que se realizó el 20 y \\
21 de junio para el ciclo escolar $2015-2016$, luego de que la SEP suspendió la realización de la prueba \\
una semana antes de las elecciones del 7 de junio, lo que generó críticas de diversos sectores de la \\
sociedad, incluso el registro de una denuncia de la organización Mexicanos Primero ante la Suprema \\
Corte de Justicia de la Nación. \\
- El secretario de Educación Pública se reunió con los gobernadores de Chiapas, Manuel Velasco \\
Coello; de Oaxaca, Gabino Cué; de Guerrero, Héctor Astudillo Flores, y de Michoacán, Silvano \\
Aureoles Conejo, para revisar los avances y estrategias sobre la aplicación de la evaluación docente. \\
Al comparecer ante la Cámara de Diputados, el titular de la Secretaría de Educación Pública, Aurelio \\
Nuño, afirmó que mantendrá un diálogo muy cercano y de claridad con el Sindicato Nacional de \\
Trabajadores de la Educación para no confundir roles ni papeles.
\end{tabular}

Crítico - El presidente de la Cámara de Diputados, Jesús Zambrano Grijalva (PRD), dijo que quienes critican la reforma educativa tienen en parte razón, pues se quedó esencialmente en materias administrativas y de carácter laboral, pese a que ese no era el objetivo, aunque era absolutamente necesario que se empezara a transitar por ahí. 


\section{CUADRO 2. Ejemplos de codificación del tono de la nota (continuación)}

\begin{tabular}{ll}
\hline Categoria & Ejemplos \\
\hline Crítico & Roberto Rodríguez, especialista del Instituto de Investigaciones Sociales de la Universidad Nacional \\
& Autónoma de México (UNAM), consideró que esta reforma es un principio de organización, no de \\
& aplicación de políticas diferenciadas; tampoco cambiará la relación con las secciones sindicales. \\
& Consideró que este espacio podría servir para la elaboración final del modelo educativo y la \\
contextualización de las evaluaciones, lo que podría desactivar a la disidencia magisterial. \\
- "Con la reforma educativa se logró que, por primera vez en muchos años, el tema de la educación \\
se ubique en el centro del interés de todos los actores políticos, sociales y económicos del país y \\
este momento se debe aprovechar para alcanzar la calidad educativa, que únicamente se logrará al \\
poner en marcha todas las acciones de la reforma y que cada actor, en su campo de acción, cumpla \\
con la siguiente parte que le obliga la ley: el acompañamiento, el desarrollo profesional, la formación \\
continua con cursos de capacitación y un sistema profesional de desarrollo pertinente con lo que la \\
reforma plantea", manifestó el presidente del Sindicato Nacional de Trabajadores de la Educación, Juan \\
Díaz de la Torre, al inaugurar la Sesión Extraordinaria del Secretariado Nacional, en Guadalajara, Jalisco.
\end{tabular}

En contra - La Coordinadora Nacional de Trabajadores de la Educación dio a conocer que iniciará una nueva etapa de resistencia en contra de la reforma educativa, en el marco de lo cual se gesta la insurgencia magisterial con mayor fuerza.

- Rubén Núñez Ginez, secretario general de la Coordinadora Nacional de Trabajadores de la Educación en Oaxaca, inició una campaña entre los maestros de la entidad para advertirles que si llegan a participar en alguno de los exámenes de la reforma educativa serán "separados o despedidos" de su trabajo.

- Trece secciones afines a la Coordinadora Nacional de Trabajadores de la Educación se unieron para realizar acciones conjuntas en contra de la reforma educativa y acordaron no iniciar el ciclo escolar 2015-2016 por un periodo de 48 horas a partir del 24 de agosto.

- La Asamblea Nacional Representativa de la Coordinadora Nacional de Trabajadores de la Educación, determinó en Oaxaca valorar la propuesta de no iniciar el ciclo escolar 2015-2016, en rechazo a la evaluación que plantea la Secretaría de Educación Pública y acordó crear una cuenta alterna en apoyo económico a la Sección 22 del SNTE.

Fuente: Elaboración propia.

tuvieron un cierto equilibrio entre el porcentaje de notas a favor y en contra, destacando particularmente Reforma, donde el porcentaje de notas a favor y en contra es bastante similar (cuadro 3). Encontramos que del total de notas que focalizaron su atención en la RE (4206), 41 por ciento publicó notas que reflejan un total rechazo y 41.3 por ciento una posición favorable.

La RE y sus leyes secundarias destacaron por introducir un conjunto de decisiones y acciones que dieron lugar a importantes cambios no incrementales en el sistema educativo mexicano. Destaca que la evaluación docente y el Servicio Profesional Docente fueron los temas más mencionados por los periódicos analizados con 29.9 y 24.63 por ciento, respectivamente. La calidad educativa y el 
CUADRO 3. Tono de las notas por periódico

\begin{tabular}{lrrrrr}
\hline Medio/Tono & A favor & Neutro & \multicolumn{1}{c}{ Critico } & En contra & Total \\
\hline ElUniversal & $654(56.38)$ & $99(8.53)$ & $116(10.00)$ & $291(25.09)$ & 1160 \\
Reforma & $464(40.92)$ & $40(3.53)$ & $153(13.49)$ & $477(42.06)$ & 1134 \\
ElFinanciero & $180(44.67)$ & $40(9.93)$ & $40(9.93)$ & $143(35.48)$ & 403 \\
La Jornada & $440(29.16)$ & $76(5.04)$ & $178(11.80)$ & $815(54.01)$ & 1509 \\
Total & 1738 & 255 & 487 & 1726 & 4206 \\
\hline
\end{tabular}

Fuente: Elaboración propia. Chi cuadrada $<0.05$. Porcentajes entre paréntesis.

INEE fueron los siguientes temas más mencionados en las notas con 15.5 y 11.13 por ciento, respectivamente. Si se agrupan todos los temas relacionados con evaluación (SPD, SNEE, INEE, evaluación docente, evaluación educativa) se tiene que la cobertura alcanzó 72.6 por ciento, lo que permite afirmar que la atención mediática estuvo centrada principalmente en la evaluación. Los temas restantes recibieron una cobertura de apenas entre uno y 6 por ciento, es decir, estuvieron

GRÁFICA 3. Tono de las notas que cubren la reforma educativa

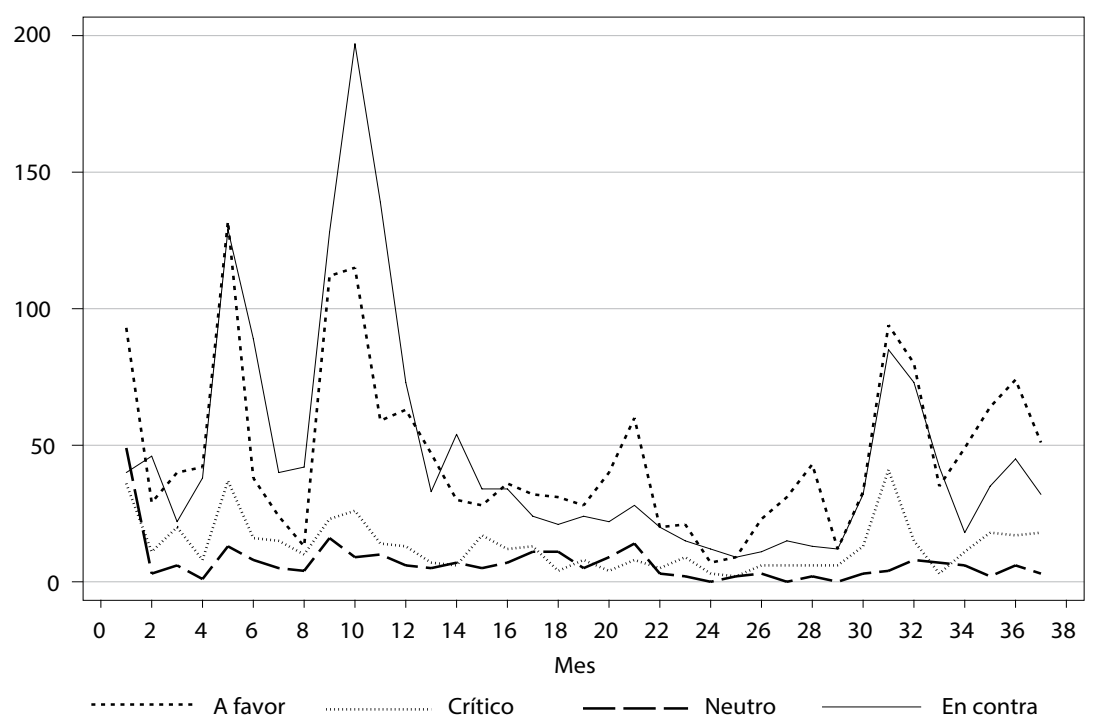

Fuente: Elaboración propia. 
CUADRO 4. Menciones de las variables temáticas analizadas

\begin{tabular}{lcc}
\hline Temas & Frecuencia & Porcentaje \\
\hline Rectoría del Estado & 132 & 3.14 \\
Artículo 3 & 551 & 13.1 \\
Servicio Profesional Docente & 1036 & 24.63 \\
Sistema Nacional de Evaluación & 98 & 2.33 \\
INEE & 468 & 11.13 \\
Evaluación docente & 1258 & 29.91 \\
Evaluación educativa & 199 & 4.73 \\
Siged & 64 & 1.52 \\
Censo & 150 & 3.57 \\
Autonomía de la gestión escolar & 109 & 2.59 \\
Infraestructura & 250 & 5.94 \\
Modelo educativo & 184 & 4.37 \\
Idoneidad & 99 & 2.35 \\
Tiempo completo & 98 & 2.33 \\
Alimentos & 45 & 1.07 \\
Calidad educativa & 651 & 15.48 \\
Calidad como derecho & 80 & 1.9 \\
Aprendizaje & 70 & 1.66 \\
Equidad & 128 & 3.04 \\
\hline
\end{tabular}

Fuente: Elaboración propia.

prácticamente ausentes en la cobertura, tal es el caso de la rectoría del Estado y la calidad como derecho, que fueron dos de los cambios sustanciales de esta reforma (cuadro 4).

La calidad educativa fue uno de los temas que aparecieron con mayor frecuencia en las notas analizadas (15.5\% del total de notas), aunque las menciones son significativamente menores que las menciones a la evaluación docente o al servicio profesional docente. Sin embargo, destaca que las menciones a la calidad como derecho son marginales (1.9\%), siendo éste uno de los aspectos más importantes que fueron reformados y que justifican gran parte de las otras modificaciones introducidas. Las menciones al aprendizaje y la equidad también fueron marginales (1.66 y 3.04\%, respectivamente) (véase gráfica 4).

La rectoría del Estado, la evaluación docente y el Servicio Profesional Docente representan tres grandes ejes de la reforma. Los dos últimos fueron de los temas más mencionados en las notas, sin embargo, la rectoría del Estado recibió un menor número de menciones (este eje se menciona en 3.14\% de las notas). El periodo 
GRÁFICA 4. Menciones a la calidad educativa, el aprendizaje, la calidad como derecho y la equidad

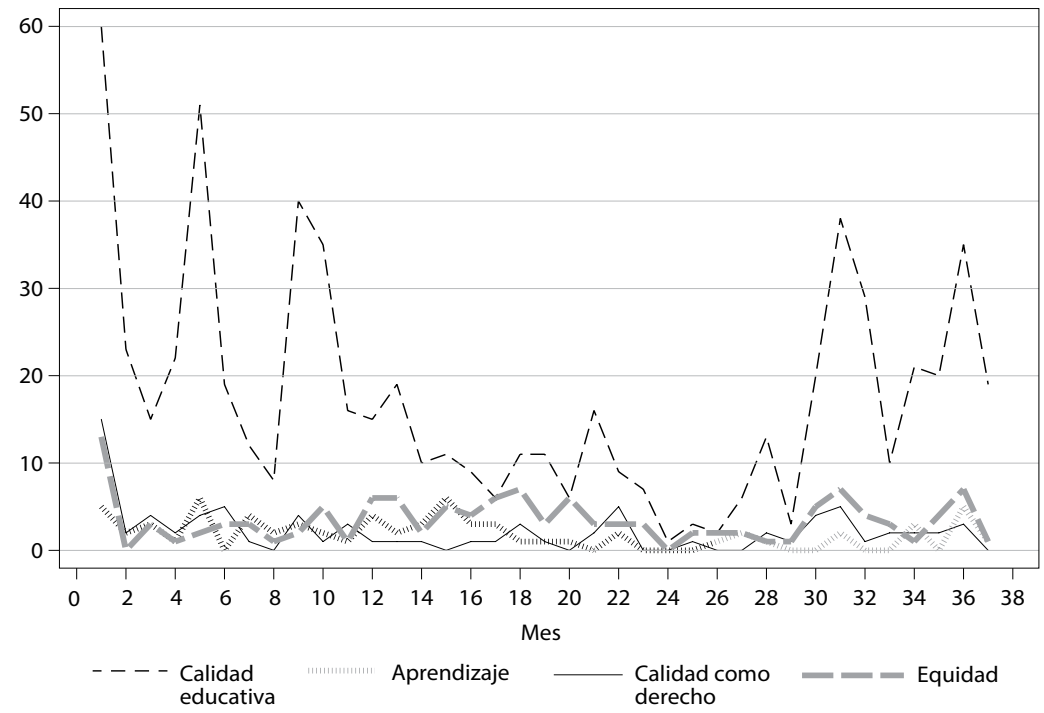

Fuente: Elaboración propia.

en el que se registra un mayor número de notas relacionadas con la evaluación docente fue el comprendido entre junio y julio de 2015 (gráfica 5), que coincide con decisiones y acciones políticas clave.

La evaluación docente fue un tema central y propició un debate polarizado y una serie de resistencias por parte de grupos diversos. La evaluación docente como uno de los ejes principales de la reforma se puede analizar a su vez en cuatro variables: el sistema nacional de evaluación, el INEE, la evaluación docente y la evaluación educativa. Destaca que, de todas las variables relacionadas con el aspecto más general de la evaluación, es la evaluación docente la que recibe un mayor número de menciones, mismas que incrementan en la segunda mitad de 2015, cuando se registran las resistencias a incorporar las leyes secundarias (gráfica 6).

A lo largo de este artículo hemos sostenido que la RE destacó por haber incorporado modificaciones en una diversidad considerable de temas y que la cobertura se centró principalmente en los aspectos relacionados con la evaluación, dejando de lado otros temas relevantes. Es importante destacar que una misma 
GRÁFICA 5. Menciones a los tres ejes de la reforma educativa

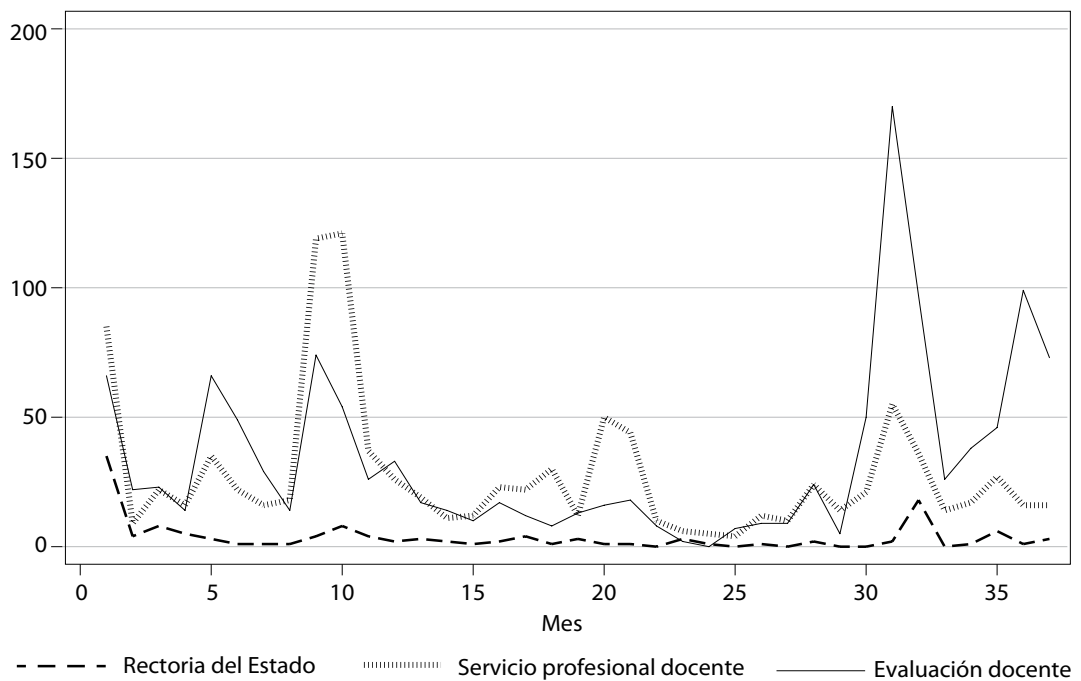

Fuente: Elaboración propia.

GRÁFICA 6. Menciones a temas relacionados con la evaluación

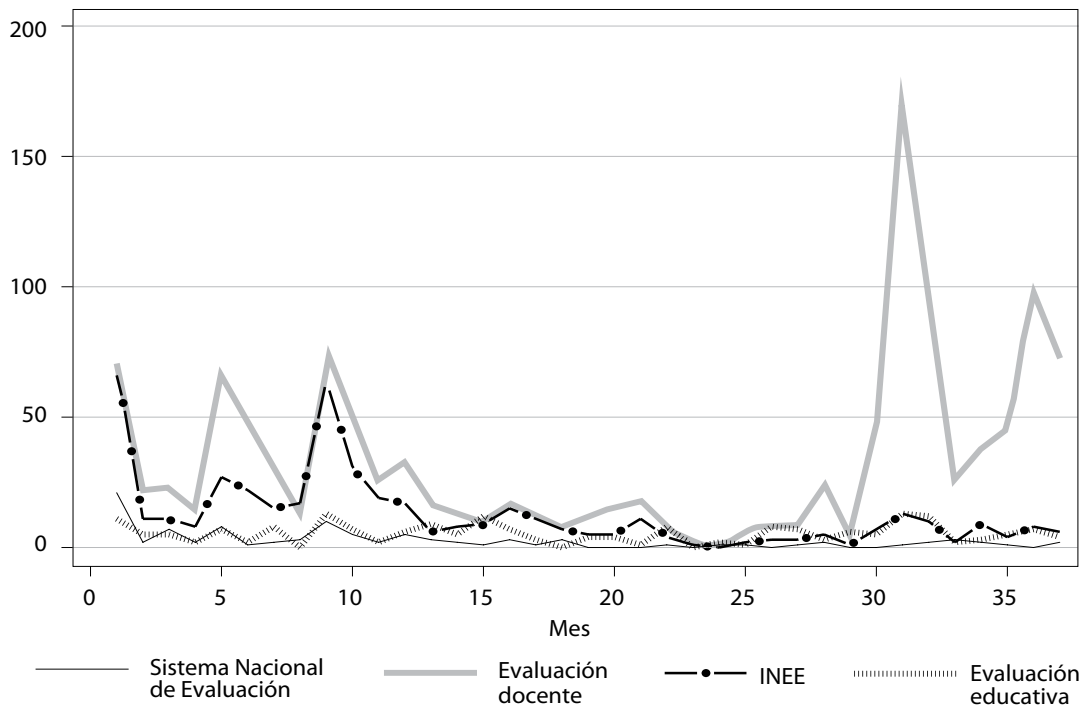

Fuente: Elaboración propia. 
CUADRO 5. Número de temas por periódico

\begin{tabular}{lccccc}
\hline Número de temas & Obs. & Media & $\begin{array}{c}\text { Desviación } \\
\text { estándar }\end{array}$ & Mínimo & Máximo \\
\hline ElUniversal & 1160 & 1.6 & 1.55 & 0 & 15 \\
Reforma & 1134 & 1.35 & 1.56 & 0 & 11 \\
ElFinanciero & 403 & 1.03 & 1.33 & 0 & 10 \\
La Jornada & 1509 & 1.24 & 1.24 & 0 & 9 \\
Total & 4206 & 1.35 & 1.44 & 0 & 15 \\
\hline
\end{tabular}

Fuente: Elaboración propia.

nota puede contener uno o varios temas. Por lo tanto, podemos decir que cuanto mayor sea el número de temas mencionados en una nota, se brinda mayor información del marco general de la reforma.

Se construyó una variable que suma el número de temas mencionados en cada nota. El rango de esta variable va de 0 a 15 temas y la media de temas por nota es de apenas 1.35 temas con una desviación estándar de 1.44. La media de temas por nota es bastante similar en todos los periódicos analizados. Destaca el periódico El Universal, el cual tiene la media más alta de temas por nota con casi dos temas por nota (cuadro 5).

\section{LOS ACTORES DE LA REFORMA EDUCATIVA EN LA PRENSA MEXICANA}

La segunda parte del análisis buscó identificar qué cobertura recibieron los actores de la RE y qué agenda política generaron los periódicos. Los actores gubernamentales son los que ocupan un cargo en el gobierno federal y en los gobiernos locales. Los actores no gubernamentales son los actores sindicales (SNTE, CNTE), la disidencia magisterial, maestros y normalistas no organizados, la sociedad civil, los partidos políticos, el INEE, los expertos, las instituciones de educación superior y la Suprema Corte de Justicia.

Se encontraron 14 categorías de actores presentes en la cobertura. El actor que tuvo mayor presencia en los periódicos analizados fue la CNTE con 26 por ciento de las notas, seguido del gobierno federal con 17.95 por ciento de las notas. La sociedad civil, que es una categoría amplia donde se agrupan empresarios, iglesias, organizaciones de la sociedad civil, entre otras, recibió 9.4 por ciento de la cobertura. Es importante destacar que actores como los maestros normalistas no organizados, la Suprema Corte de Justicia de la Nación, los funcionarios estatales $y$ el INEE fueron los actores que recibieron una cobertura marginal (cuadro 6). 
CUADRO 6. Cobertura de los actores de la reforma educativa

\begin{tabular}{lcc}
\hline Actor & Frecuencia de notas & Porcentaje \\
\hline Presidente de la República & 191 & 4.54 \\
Gobierno federal & 755 & 17.95 \\
SNTE & 344 & 8.18 \\
CNTE & 1094 & 26.01 \\
Poder Legislativo & 252 & 5.99 \\
Sociedad civil & 396 & 9.42 \\
Partidos políticos & 211 & 5.02 \\
Funcionarios estatales & 143 & 3.40 \\
INEE & 119 & 2.83 \\
Disidencia magisterial & 140 & 3.33 \\
Sector educativo/expertos & 349 & 8.30 \\
Maestros normalistas no organizados & 49 & 1.17 \\
Otros & 137 & 3.26 \\
\hline
\end{tabular}

Fuente: Elaboración propia.

Se encontraron diferencias importantes en la presencia de los actores de la RE por periódico analizado. Por un lado, destaca que las notas donde el presidente de la República, el Poder Legislativo, los partidos políticos y la Suprema Corte de Justicia de la Nación fueron los actores principales, estuvieron concentradas en el periódico El Universal. Por otro lado, aquellas notas donde la CNTE, la sociedad civil, los funcionarios estatales, el INEE, la disidencia magisterial, el sector educativo y expertos y los maestros normalistas no organizados fueron el actor principal, estuvieron concentradas en el periódico La Jornada. Destaca el caso del SNTE y el gobierno federal que lograron permear de forma indistinta todos los medios analizados (cuadro 7).

Para identificar coaliciones promotoras y opositoras de la RE, se realizó un crosstab con el tono de las notas y los actores. Del total de notas cuyo tono era a favor de la reforma (1 738 notas), 10.59 por ciento corresponden a notas donde el actor principal es el presidente de la República y 38.72 por ciento corresponden a notas donde diversas ramas del gobierno federal son el actor principal. Asimismo, el total de notas a favor de la reforma donde la sociedad civil es el actor predominante es de 10.36 por ciento. 
CUADRO 7. Actores de la reforma educativa y medio

\begin{tabular}{lccccc}
\hline Actor & Frecuencia & $\begin{array}{c}\text { El Universal } \\
\text { (porcentaje) }\end{array}$ & $\begin{array}{c}\text { Reforma } \\
\text { (porcentaje) }\end{array}$ & $\begin{array}{c}\text { El Financiero } \\
\text { (porcentaje) }\end{array}$ & $\begin{array}{c}\text { La Jornada } \\
\text { (porcentaje) }\end{array}$ \\
\hline Presidente de la República & 191 & 49.74 & 24.08 & 11.52 & 14.66 \\
Gobierno federal & 755 & 36.42 & 21.32 & 6.89 & 35.36 \\
SNTE & 344 & 30.52 & 29.36 & 9.88 & 30.23 \\
CNTE & 1094 & 17.73 & 29.07 & 8.68 & 44.52 \\
Poder Legislativo & 252 & 39.68 & 18.25 & 25.00 & 17.06 \\
Sociedad civil & 396 & 18.18 & 44.70 & 8.84 & 28.28 \\
Partidos políticos & 211 & 57.82 & 23.70 & 6.64 & 11.85 \\
Funcionarios estatales & 143 & 18.18 & 24.48 & 20.28 & 37.06 \\
INEE & 119 & 26.89 & 18.49 & 0.00 & 54.62 \\
Disidencia magisterial & 140 & 10.71 & 31.43 & 20.00 & 37.86 \\
Sector educativo/expertos & 349 & 24.07 & 26.36 & 3.15 & 46.42 \\
Normalistas no organizados & 49 & 10.20 & 22.45 & 6.12 & 61.22 \\
SCJN & 26 & 50.00 & 15.38 & 15.38 & 19.23 \\
Otros & 137 & 16.06 & 19.71 & 9.49 & 54.74 \\
Total & 4206 & 27.58 & 26.96 & 9.58 & 35.88 \\
\hline
\end{tabular}

Fuente: Elaboración propia. Chi cuadrada $<0.05$.

Las notas donde el presidente de la República, el gobierno federal o los funcionarios estatales son el actor principal, son notas a favor de la RE. Asimismo, las notas donde la CNTE y los maestros normalistas son el actor principal, son notas en contra de la reforma. Destaca el caso en el que el SNTE es el actor principal porque las notas se encuentran ubicadas en los dos polos opuestos de la escala (a favor y en contra), lo que sugiere una polarización al interior del SNTE que se ve reflejada en las notas periodísticas (cuadro 8).

El número de temas por nota es una variable relevante para medir la cantidad de información que contienen las notas periodísticas de la RE. Si analizamos esto por actores podemos tener un aproximado de la cantidad de temas que cada actor intentaba posicionar en la agenda política. Destaca el caso de los actores gubernamentales, como el presidente de la República, el gobierno federal, el Poder Legislativo, el INEE y la SCJN, que es donde se registran las medias de temas más altas por nota. Como era de esperarse, las notas donde el sector educativo y 
CUADRO 8. Actores de la reforma educativa y tono de las notas

\begin{tabular}{lccccc}
\hline Actor & Frecuencia & $\begin{array}{c}\text { A favor } \\
\text { (porcentaje) }\end{array}$ & $\begin{array}{c}\text { Neutro } \\
\text { (porcentaje) }\end{array}$ & $\begin{array}{c}\text { Crítico } \\
\text { (porcentaje) }\end{array}$ & $\begin{array}{c}\text { En contra } \\
\text { (porcentaje) }\end{array}$ \\
\hline Presidente de la República & 191 & 96.34 & 3.66 & 0.00 & 0.00 \\
Gobierno federal & 755 & 89.14 & 9.93 & 0.40 & 0.53 \\
SNTE & 344 & 38.66 & 1.16 & 16.86 & 43.31 \\
CNTE & 1094 & 0.55 & 0.73 & 1.55 & 97.17 \\
Poder Legislativo & 252 & 54.76 & 21.83 & 18.65 & 4.76 \\
Sociedad civil & 396 & 45.45 & 0.51 & 27.02 & 27.02 \\
Partidos políticos & 211 & 54.50 & 1.90 & 19.43 & 24.17 \\
Funcionarios estatales & 143 & 71.33 & 7.69 & 11.89 & 9.09 \\
INEE & 119 & 67.23 & 16.81 & 15.97 & 0.00 \\
Disidencia magisterial & 140 & 0.00 & 0.00 & 2.14 & 97.86 \\
Sector educativo yexpertos & 349 & 30.09 & 1.15 & 42.98 & 25.79 \\
Normalistas no organizados & 49 & 0.00 & 0.00 & 6.12 & 93.88 \\
SCJN & 26 & 34.62 & 65.38 & 0.00 & 0.00 \\
Otros & 137 & 9.49 & 35.04 & 16.06 & 39.42 \\
Total & 4206 & 41.32 & 6.06 & 11.58 & 41.04 \\
\hline
\end{tabular}

Fuente: Elaboración propia. Chi cuadrada $<0.05$.

los expertos en educación son los actores principales, también tienen la media de temas más alta. Lo contrario ocurre con las notas donde la CNTE, la disidencia y los normalistas no organizados son el actor principal (cuadro 9).

Hasta aquí se ha presentado un análisis de la cobertura mediática que recibió la RE en cuatro periódicos mexicanos de circulación nacional. En un principio establecimos que, si bien la RE está presente en la prensa escrita, las notas informan de manera parcial y fragmentada: parcial porque destacan en mayor medida el tema de la evaluación y el conflicto asociado y fragmentada porque las notas a través de las cuales se cubre la reforma no dan cuenta cabal del conjunto de temas que le dan sentido. El hecho de que la evaluación y el conflicto reciban mayor atención que cualquier otro tema favorece la atención prestada por la prensa nacional a los actores que asumen una posición en contra. $\mathrm{Al}$ analizar el tono de las notas pudimos identificar una coalición promotora encabezada por actores gubernamentales y una coalición opositora encabezada por la CNTE. 
CUADRO 9. Temas por nota y actores. Descriptivos

\begin{tabular}{lrrccc}
\hline Actor & Obs. & Media & $\begin{array}{c}\text { Desviación } \\
\text { estándar }\end{array}$ & Mínimo & Máximo \\
\hline Presidente de la República & 191 & 2.25 & 2.09 & 0 & 13 \\
Gobierno federal & 755 & 1.73 & 1.47 & 0 & 15 \\
SNTE & 344 & 1.19 & 1.28 & 0 & 6 \\
CNTE & 1094 & 0.71 & .89 & 0 & 6 \\
Poder Legislativo & 252 & 1.98 & 1.91 & 0 & 11 \\
Sociedad civil & 396 & 1.5 & 1.46 & 0 & 8 \\
Partidos políticos & 211 & 1.47 & 1.55 & 0 & 10 \\
Funcionarios estatales & 143 & 1.00 & 1.09 & 0 & 7 \\
INEE & 119 & 2.01 & 1.28 & 0 & 8 \\
Disidencia magisterial & 140 & 0.35 & .59 & 0 & 3 \\
Sector educativo y expertos & 349 & 1.94 & 1.37 & 0 & 7 \\
Normalistas no organizados & 49 & 0.63 & .75 & 0 & 2 \\
SCJN & 26 & 1.73 & 1.25 & 0 & 4 \\
Otros & 137 & 1.18 & 1.15 & 0 & 6 \\
Total & 4206 & 1.35 & 1.44 & 0 & 15 \\
\hline
\end{tabular}

Fuente: Elaboración propia.

\section{CONCLUSIONES: LA AGENDA POLÍTICA DE LOS MEDIOS Y LA REFORMA EDUCATIVA}

El objetivo de esta investigación fue realizar un estudio descriptivo sobre la cobertura que recibió la RE, para destacar el vínculo entre los medios y el proceso de las políticas. Los medios juegan un papel estratégico al construir una atención mediática: son un actor que decide qué hacer visible y qué no y adquieren relevancia tanto para los políticos como para la ciudadanía. Para los primeros, monitorear a los medios es un ejercicio obligado para tomar decisiones políticas y de políticas entre las cuales destacan las relacionadas con sus estrategias de comunicación y difusión, expresamente para acompañar los procesos de políticas en abono de un proceso exitoso de cambios; mientras que para la ciudadanía, los medios constituyen una fuente de información acerca de lo que pasa en el mundo de la política.

Si el proceso de políticas implica una complejidad en la que convergen distintos actores, decisiones y momentos, los medios de comunicación participan en este proceso modificando los ciclos de atención hacia ciertos temas. Sin embargo, la evidencia acerca del efecto que tienen los medios en los resultados de 
una política concreta no es todavía concluyente. Lo que se sabe hoy sobre la función de los medios en este proceso radica en la importancia de conocer los ciclos de atención para elaborar conclusiones acerca de las posibles implicaciones que tiene esto en la toma de decisiones. Sin embargo, como demuestra Wolfe (2012), la atención de los medios es fundamental en el proceso de políticas, pero no así en el resultado final de una política concreta.

Parte de la complejidad del proceso de políticas radica en la multiplicidad de actores, decisiones y procesos que convergen. La importancia de incorporar a los medios en este análisis consiste en la capacidad que tienen para fijar la atención en temas determinados, que pueden o no ser los temas calificados como sustanciales en un proceso de reforma. Entonces, los medios de comunicación tienen la capacidad de orientar un debate, moldear decisiones y orientar opiniones de diversos actores y, con ello, fijar el rumbo de las políticas.

Algunos autores han establecido que la influencia de los medios en las políticas públicas es mucho más visible en las etapas primarias del proceso de políticas, cuando se inicia el establecimiento de la agenda (Kingdon, 1984; Baumgartner y Jones, 1993; Wolfe, Jones y Baumgartner, 2013). Los medios juegan un papel estratégico en el proceso de las políticas al decidir qué merece o no atención, aun cuando se debata si su relevancia es mayor en las primeras etapas del proceso o a lo largo del mismo (Wolfe, 2012).

En primer lugar, destaca que la cobertura mediática que recibió la RE fue amplia en cantidad, estuvo orientada hacia ciertos temas particulares y además estuvo muy polarizada. El comportamiento de la cobertura responde a la coincidencia entre decisiones políticas controvertidas para algunos actores (CNTE). El cambio no incremental de la reforma, que trastocó los derechos laborales del magisterio en servicio, explica en buena parte tanto el conflicto político gobierno federalCNTE, que paralizó la RE durante 2013-2015, como el tamańo y los rasgos de la cobertura mediática que recibió la RE.

En términos de contenido, los cuatro periódicos tienen un comportamiento similar: cada una de las notas cubre poco más de un tema aunque hay tres cambios no incrementales de suma relevancia y por lo menos otros 16 que representan cambios incrementales, pero no por ello menos importantes. Sólo algunos cambios no incrementales recibieron una cobertura mediática significativa, como es el caso del conjunto de temas relacionados con la evaluación (evaluación docente, evaluación educativa, SPD, SNE, INEE), que representa 72.6 por ciento de la cobertura, siendo la evaluación docente $(29.9 \%)$ y el SPD $(24.6 \%)$ los de mayor cobertura. Otros cambios de similar magnitud recibieron una cobertura signifi- 
cativamente menor: la rectoría del Estado (3.14\%), la reforma al artículo $3^{\circ}$ constitucional (13.1\%), equidad (3.04\%) y calidad como derecho (1.9\%).

En cuanto a la polarización, destaca que del total de notas que focalizaron su atención en la reforma (4206), 41 por ciento expresa un total rechazo y 41.3 por ciento expresa una posición favorable. Es El Universal el medio que registra un mayor porcentaje de notas a favor $(56.4 \%)$, mientras que La Jornada destaca por la proporción de notas en contra (54.01\%). De esta manera, El Universal es el medio que acoge a la coalición promotora y La Jornada a la coalición opositora.

El conflicto, la resistencia y el rechazo político de amplios segmentos sociales son los rasgos que distinguen a la RE. Entre febrero y septiembre de 2013, se registran manifestaciones que dan cuenta del tamaño del desacuerdo: la disidencia se apostó en espacios públicos simbólicos de la Ciudad de México como el Zócalo y el Monumento a la Revolución; la disidencia magisterial de Oaxaca, Chiapas, Michoacán y Guerrero amenazó constantemente con la declaración de paros indefinidos de clases especialmente en los inicios del ciclo escolar, lo cual dio lugar a la suspensión de clases durante varias semanas y constantes diálogos con la Secretaría de Gobernación; en Oaxaca, destaca la propuesta de un modelo educativo alternativo (el Plan para la Transformación en la Educación) en sustitución de la RE y el hecho de que fue el último estado que armonizó su ley estatal de educación con la ley federal (11 de abril de 2016).

Algunas de las condiciones que establecen el marco de relación entre medios y política pública obedecen a las dinámicas específicas de cada política (Voltmer y Koch-Baumgarten, 2010), a la incertidumbre política y al consenso entre las élites (Robinson, 2001), donde la incertidumbre política, el conflicto y los temas que por su naturaleza son más noticiosos generan más cobertura, así como también a la prominencia y el nivel de "sensacionalismo" que tienen los temas (Soroka, 2002). En este sentido, las noticias se convierten en una fuente de monitoreo del entorno político (Deutsch, 1963).

El número de notas con una postura en contra de la reforma registran mayores niveles cuando se presentan las principales manifestaciones de resistencia a la aprobación de las leyes secundarias y cuando tienen lugar decisiones y acciones políticas de alto impacto. Destaca que los meses en los que la RE recibió una mayor cobertura coinciden con el momento en que se presentan manifestaciones directas del conflicto.

En este sentido, se puede hacer referencia al interés noticioso de los medios de comunicación que, a su vez, tiene un efecto en el entendimiento global de los problemas públicos. Estos conflictos estuvieron ligados principalmente al 
tema de la evaluación educativa, el cual, a su vez, fue el que recibió mayor atención por parte de los medios. Estos hallazgos nos permiten reforzar la idea del interés noticioso de los medios y el papel del conflicto en los cambios de política.

La configuración de la agenda de políticas consiste en organizar la atención en un entorno con información, intereses, problemas e ideas competitivas y una capacidad de procesamiento limitada (Jones y Baumgartner, 2005). La reforma educativa representó un constante desafío a la estabilidad política producido por la resistencia y un empate político en el sistema mediático entre la coalición opositora y la coalición promotora. El análisis de actores realizado a través de la codificación de las notas periodísticas permite dar sustento a esta idea. Asimismo, la información existente en torno a la reforma no fluyó en una única dirección, sino en múltiples direcciones y con retroalimentación compleja dentro del sistema.

En este artículo no se establece la idea de una influencia directa de los medios en las políticas. La amplia literatura en el tema ha planteado que no es posible establecer el mecanismo causal, aunque se destaca que los medios son amplificadores de la agenda y son útiles al ponderar la información y enfocar la atención en el entorno de políticas. En este sentido, si los medios entran en la arena política tienen la capacidad de cambiar el rumbo de una política o el curso de un proceso de decisión de forma importante. Gిิ

\section{REFERENCIAS BIBLIOGRÁFICAS}

Arnaut, Alberto (2013), "Lo bueno, lo malo y lo feo del servicio profesional docente", en Gloria del Castillo y Giovanna Valenti, Reforma educativa: ¿Qué estamos transformando?, Ciudad de México: Flacso.

Atkinson, Mary Layton, John Lovett y Frank R. Baumgartner (2014), "Measuring the Media Agenda”, Political Communication, 31(2), pp. 355-380.

Avilés, Karla y Julio César Solís (2012), "Revisaremos la relación con el gobierno y los partidos: Gordillo", La Jornada, 12 de octubre, disponible en: http://www.jornada. unam.mx/2012/10/19/politica/002n1 pol [fecha de consulta: 15 de febrero de 2017].

Baumgartner, Frank R. y Bryan D. Jones (1993), Agendas and Instability in American Politics, Chicago: University of Chicago Press.

Baumgartner, Frank R., Bryan D. Jones y Beth L. Leech (1997), "Media Attention and Congressional Agendas", en S. Iyengar y R. Reeves (eds.), Do the Media Govern?, Thousand Oaks: Sage, pp. 349-363.

Boydstun, Amber E. (2013), Making the News: Politics, the Media, and Agenda Setting, Chicago: University of Chicago Press. 
Burstein, Paul (2003), "The Impact of Public Opinion on Public Policy: A Review and an Agenda", Political Research Quarterly, 56(1), pp. 29-40.

Collins, Patricia, Julia Abelson, Heather Pyman y John N. Lavis (2006), "Are We Expecting Too Much from Print Media? An Analysis of Newspaper Coverage of the 2002 Canadian Healthcare Reform Debate”, Social Science \& Medicine, 63(1), pp. 89-102.

Del Castillo, Gloria (2012), "Las políticas educativas en México desde una perspectiva de política pública: Gobernabilidad y gobernanza”, Magis: Revista Internacional de Investigación Educativa, 4(9), pp. 632-652.

Del Castillo, Gloria (2013), "El desempeño docente y el logro educativo en el centro de las políticas: ¿Hacia una gobernabilidad para la calidad?”, en Rodolfo Ramírez Raymundo (coord.), La reforma constitucional en materia educativa: Alcances y desafios, Ciudad de México: Instituto Belisario Domínguez.

Del Castillo, Gloria (2014), "Una perspectiva analítica de política pública para el análisis de problemas públicos complejos", ponencia presentada en el IV Congreso Nacional de Ciencias Sociales organizado por el Consejo Mexicano de Ciencias Sociales, San Cristóbal de las Casas, 24-28 de marzo.

Dente, Bruno y Joan Subirats (2014), Decisiones públicas: Análisis y estudio de los procesos de decisión en políticas públicas, Barcelona: Ariel.

Deutsch, Karl W. (1963), The Nerves of Government: Models of Political Communication and Control, Nueva York: The Free Press.

Downs, Anthony (1972a), "The Issue-attention Cycle and the Political Economy of Improving our Environment", en Anthony Downs, The Political Economy of Environmental Control, Berkeley: University of California Press.

Downs, Anthony (1972b), "Up and Down with Ecology: The 'Issue-attention Cycle", en David Protess y Maxwell E. McCombs (eds.), Agenda Settings: Readings on Media, Public Opinion and Policymaking, Nueva York: Routledge.

Egorov, Georgy, Sergei Guriev y Konstantin Sonin (2009), "Why Resource-poor Dictators Allow Freer Media: A Theory and Evidence from Panel Data", American Political Science Review, 103(4), pp. 645-668.

Entman, Robert M. (1991), "Symposium Framing US Coverage of International News: Contrasts in Narratives of the KAL and Iran Air Incidents", Journal of Communication, 41(4), pp. 6-27.

Entman, Robert M. (1993), "Framing: Toward Clarification of a Fractured Paradigm", Journal of Communication, 43(4), pp. 51-58.

Erikson, Robert S., Gerald C. Wright y John P. McIver (1993), Statehouse Democracy: Public Opinion and Policy in the American States, Cambridge: Cambridge University Press. Gamson, William A. (1992), Talking Politics, Cambridge: Cambridge University Press. 
Gamson, William A. y Gadi Wolfsfeld (1993), "Movements and Media as Interacting Systems", The Annals of the American Academy of Political and Social Science, 528, pp. 114-125.

Gamson, William A. y Andre Modigliani (1987), "The Changing Culture of Affirmative Action”, Research in Political Sociology, 3(1), pp. 137-177.

Gamson, William A. y Andre Modigliani (1989), "Media Discourse and Public Opinion on Nuclear Power: A Constructionist Approach", American Journal of Sociology, 95(1), pp. 1-37.

Gehlbach, Scott y Konstantin Sonin (2014), "Government Control of the Media”, Journal of Public Economics, 118, pp. 163-171.

Gitlin, Todd (1980), The Whole World is Watching: Mass Media in the Making, Berkeley y Los Ángeles: University of California Press.

Goffman, Erving (1974), Frame Analysis: An Essay on the Organization of Experience, Cambridge: Harvard University Press.

Hopmann, David N., Rens Vliegenthart, Claes de Vreese y Erik Albæk (2010), "Effects of Election News Coverage: How Visibility and Tone Influence Party Choice", Political Communication, 27(4), pp. 389-405.

Howlett, Michael, M. Ramesh y Anthony Perl (2009), Studying Public Policy. Policy Cycles and Policy Subsystems, Nueva York: Oxford University Press.

Jones, Bryan D. y Frank R. Baumgartner (2005), The Politics of Attention: How Government Prioritizes Problems, Chicago: University of Chicago Press.

Kingdon, John W. (1984), Agendas, Alternatives, and Public Policies, Londres: Pearson Education.

Koch-Baumgarten, Sigrid y Katrin Voltmer (2010), Public Policy and the Mass Media: The Interplay of Mass Communication and Political Decision Making, Nueva York: Routledge.

Lindblom, Charles E. (1979), "Still Muddling, Not Yet Through", Public Administration Review, 39(6), pp. 517-526.

Majone, Giandomenico (1992), "La factibilidad de las políticas sociales", en Luis F. Aguilar, La hechura de las politicas públicas, Ciudad de México: Miguel Ángel Porrúa.

May, Peter y Ashley Jochim (2013), "Policy Regime Perspectives: Policies, Politics and Governing”, The Policy Studies Journal, 41(3), pp. 426-452.

Mazur, Allan (2009), "American Generation of Environmental Warnings: Avian Influenza and Global Warming”, Human Ecology Review, 16(1), pp. 17-26.

McCombs, Maxwell E. (2004), Setting the Agenda: The Mass Media and Public Opinion. Cambridge: Polity Press.

McCombs, Maxwell E. y Donald L. Shaw (1972), "The Agenda-setting Function of Mass Media”, Public Opinion Quarterly, 36(2), pp. 176-187. 
McCombs, Maxwell E. y Donald L. Shaw (1993), "The Evolution of Agenda setting Research: Twenty Five Years in the Marketplace of Ideas", Journal of Communication, 43(2), pp. 58-67.

McCombs, Maxwell E., Donald L. Shaw y David H. Weaver (1997), Communication and Democracy: Exploring the Intellectual Frontiers in Agenda-setting Theory, Nueva Jersey: Lawrence Erlbaum Associates.

McCombs, Maxwell E. y Amy Reynolds (2002), "News Influence on Our Pictures of the World", en Bryant Jennings y Dolf Zillmann (eds.), Media Effects. Advances in Theory and Research, Nueva Jersey: Lawrence Erlbaum Associates.

Mintrom, Michael y Phillipa Norman (2009), "Policy Entrepreneurship and Policy Change", Policy Study Journal, 32(4), pp. 649-667.

Page, Benjamin I. y Robert Y. Shapiro (1983), "Effects of Public Opinion on Policy", American Political Science Review, 77(1), pp. 175-190.

Pan, Zhondang y Gerald M. Kosicki (1993), "Framing Analysis: An Approach to News Discourse”, Political Communication, 10(1), pp. 55-75.

Pan, Zhondang y Gerald M. Kosicki (2001), "Framing as a Strategic Action in Public Deliberation”, en Stephen D. Reese y Oscar H. Gandy (eds.), Framing Public Life: Perspectives on Media and Our Understanding of the Social World, Nueva Jersey: Lawrence Erlbaum Associates.

Petridou, Evangelina (2014), "Theories of the Policy Process: Contemporary Scholarhips and Future Directions", Policy Studies Journal, 42(1), pp. 12-32.

Pacto por México (2012), Pacto por México, disponible en: http://pactopormexico.org/ PACTO-POR-MEXICO-25.pdf [fecha de consulta: julio de 2017].

Peña Nieto, Enrique (2012), Lograr un México con educación de calidad para todos, disponible en: http://pactopormexico.org/wp-content/uploads/2012/12/Discurso-del-Presidente-de-la-Rep\%C3\%BAblica.pdf [fecha de consulta: julio de 2017].

Poy, Laura (2012), "Gordillo dice no a la reforma educativa; no es con amenazas como mejoraremos", La Jornada, 20 de diciembre, disponible en: http://www.jornada.unam. $\mathrm{mx} / 2012 / 12 / 20 /$ politica/008n1pol.

Robinson, Nick (2000), The Politics of Agenda Setting: The Car and the Shaping of Public Policy, Farham: Ashgate.

Robinson, P. (2001), "Theorizing the Influence of Media on World Politics: Models of Media Influence on Foreign Policy", European Journal of Communication, 16(4), pp. 523-544. Rogers, Everett M., James W. Dearing y Dorine Bregman (1993), "The Anatomy of Agenda Setting Research", Journal of Communication, 43(2), pp. 68-84.

Sabatier, Paul (2007), "The Need for Better Theories”, en Paul Sabatier (ed.), Theories of the Policy Process, Nueva York: Westview. 
Schlager, Edella y Christopher M. Weible (2013), "New Theories of the Policy Process", Policy Studies Journal, 41(3), pp. 389-396.

Soroka, Stuart N. (2002), "Issue Attributes and Agenda Setting by Media, the Public, and Policymakers in Canada", International Journal of Public Opinion Research, 14(3), pp. 264-285.

Strömberg, David (2001), "Mass Media and Public Policy", European Economic Review, 45(4), 652-663.

Tuchman, Gaye (1978), Making News: A Study in the Construction of Reality, Nueva York: The Free Press.

Tversky, Amos y Daniel Kahneman (1981), "The Framing Decisions and the Psychology of Choice", American Association for the Advancement of Science, 211(30), pp. 453-458.

Tversky, Amos y Daniel Kahneman (1986), "Rational Choice and the Framing of Decisions", The Journal of Business, 59(4), pp. S251-S278.

Voltmer, Katrin (2006), Mass Media and Political Communication in New Democracies, Nueva York: Routledge.

Voltmer, Katrin y Sigrid Koch-Baumgarten (2010), "Introduction: Mass Media and Public Policy: Is There a Link?”, en Sigrid Koch-Baumgarten, Katrin Voltmer (eds.), Public Policy and the Mass Media, Nueva York y Oxford: Routledge, pp. 19-32

Walgrave, Stefaan y Peter Van Aelst (2006), "The Contingency of the Mass Media's Political Agenda-Setting Power: Toward a Preliminary Theory", Journal of Communication, 56(1), pp. 88-109.

Walgrave, Stefaan y Rens Vliegenthart (2012), “The Complex Agenda-Setting Power of Protest: Demonstrations, Media, Parliament, Government, and Legislation in Belgium, 1993-2000", Mobilization: An International Quarterly, 17(2), pp. 129-156.

Wolfe, Michelle (2012), "Putting on the Brakes or Pressing on the Gas? Media Attention and the Speed of Policymaking”, Policy Studies Journal, 40(1), pp. 109-126.

Wolfe, Michelle, Bryan D. Jones y Frank R. Baumgartner (2013), "A Failure to Communicate: Agenda Setting in Media and Policy Studies", Political Communication, 30(2), pp. 175-192.

Gloria Del Castillo Alemán. Es doctora en Ciencias Sociales con especialización en Ciencia Política por la Flacso México. Maestra en Políticas Públicas por la Universidad Autónoma Metropolitana-Xochimilco (UAM-X). Licenciada en Ciencias Sociales por el Instituto Tecnológico Autónomo de México (ITAM). Profesora-investigadora de tiempo completo en la Flacso desde 2003 hasta la fecha. Premio Nacional Anuies (2004) a la mejor tesis de doctorado en Educación Superior. Miembro del Sistema Nacional de 
Investigadores, de la Academia Mexicana de las Ciencias y de la Policy Sciences Society. Su trabajo de investigación se focaliza en tres áreas: el estudio y análisis de políticas públicas; los avances teórico-metodológicos en el campo de política pública y el análisis de las políticas educativas como uno de sus principales referentes empíricos. Entre sus publicaciones destacan: La reforma y las políticas educativas. Impacto en la supervisión escolar (2009) y "Una perspectiva analítica de política pública para el análisis de problemas públicos complejos” (2014).

Georgina Flores Ivich. Es maestra en Ciencias Sociales por la Flacso México. Actualmente estudia el doctorado en Ciencia Política en la Universidad Nacional Autónoma de México. Es profesora-investigadora adjunta en la Flacso México y profesora de asignatura en la Universidad Panamericana y en la Facultad de Ciencia Política de la UnAm. Ha participado en diversos proyectos de consultoría e investigación académica nacionales e internacionales financiados por instituciones como Naciones Unidas, USAID, RAND Corporation, Fundación Telefónica, Inmujeres y Flacso, entre otras. Sus trabajos más recientes han sido publicados en la revista Estudios Sociológicos (2017), en el Journal of Comparative and International Education (2013), en la revista Psicología Politica de la Universidad de Valencia (2012) y en libros como: Poderes y democracias. La politica subnacional en México (2016), entre otros. Actualmente trabaja en un proyecto de investigación sobre el efecto electoral e institucional de los escándalos de corrupción en América Latina. 
